\title{
La iglesia de Nuestra Señora del Castillo (Calatañazor, Soria). Un gran edificio moderno de compleja secuencia medieval
}

\section{The church of Nuestra Señora del Castillo (Calatañazor, Soria). A big modern building with a complex medieval sequence}

\author{
Carlos Cauce \\ Instituto de Historia, CSIC. Madrid. \\ e-mail: carlos.cauce@cchs.csic.es \\ José Ignacio Murillo \\ Arqueólogo, Urbe pro Orbe. Madrid. \\ e-mail: jimurillo@urbeproorbe.com
}

\begin{abstract}
RESUMEN
La iglesia de Nuestra Señora del Castillo ha generado pocos estudios dentro de la historiografía dedicada al Románico en la provincia de Soria. Estos, fundamentalmente, se centraban en la existencia de un edificio románico en su hastial occidental y la presencia, en la misma fachada, de una alta estructura con remate semicircular identificada como una espadaña prerrománica. Sin embargo, la secuencia estratigráfica identificada en sus muros nos permite revisar estas propuestas mostrando un edificio con numerosas reformas y transformaciones de época medieval y moderna
\end{abstract}

Palabras clave: Lectura de paramentos, Románico, torre de campanas, claustra.

\section{ABSTRACT}

The church of Nuestra Señora del Castillo has been rarely the subject of that works devoted to the Romanesque in the province of Soria. These studies have mainly focused on the presence of a Romanesque building and of a high structure with a semicircular upper ending, thought to be a Pre-Romanesque bell-tower (espadaña), both of them preserved in the western façade. Nevertheless, the stratigraphic sequence of its walls show a complex building embracing several reforms and transformations occurred in the Medieval and Modern periods.

Keywords: building recording, Romanesque, bell-tower, claustra.

Recibido: 26 mayo 2014. Aceptado: 17 julio 2014.

\section{Cómo citar este artículo / Citation}

Cauce, C. y Murillo, J. I.: "La iglesia de Nuestra Señora del Castillo (Calatañazor, Soria). Un gran edificio moderno de compleja secuencia medieval", Arqueología de la Arquitectura, 11: e019. doi: http://dx.doi.org/10.3989/arq.arqt.2014.173.

\section{Copyright}

(c) 2014 CSIC. Este es un artículo de acceso abierto distribuido bajo los términos de la licencia Creative Commons Attribution-Non Commercial (by-nc) Spain 3.0. 


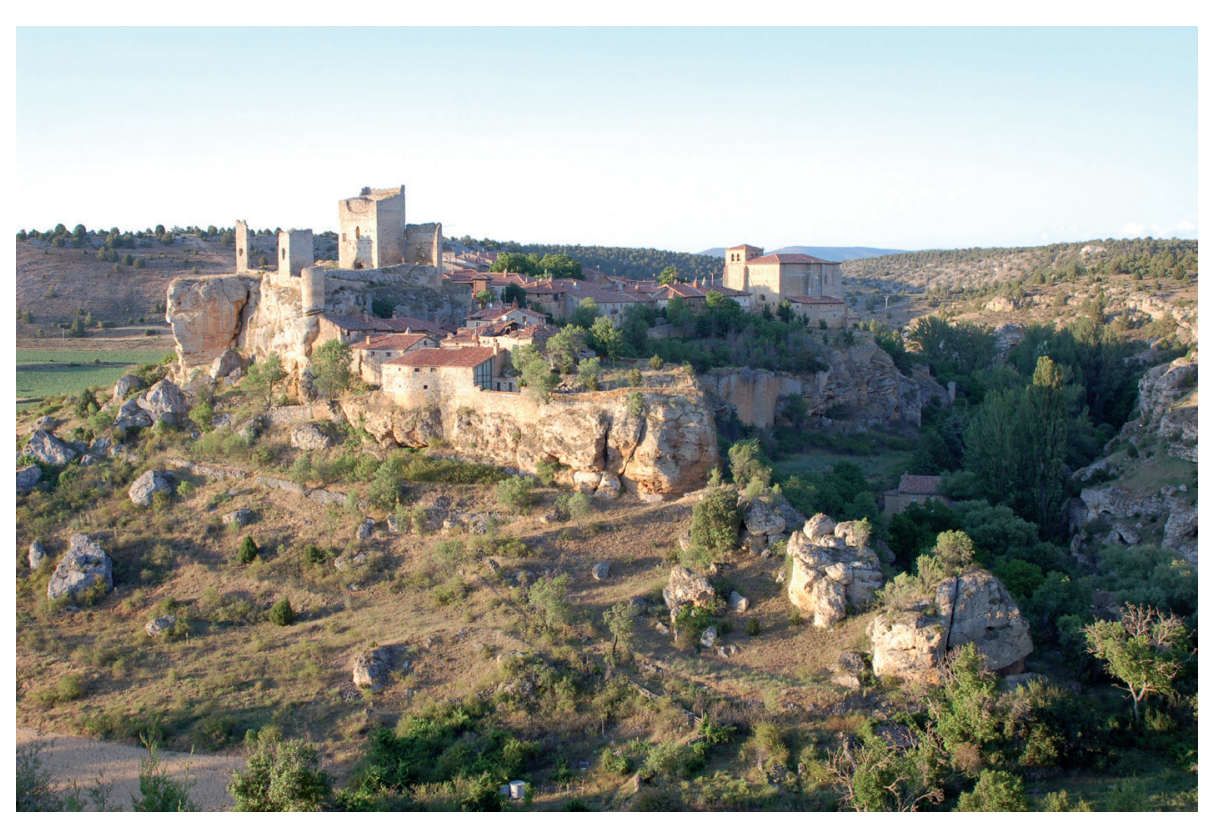

Fig. 1. Vista General de la localidad de Calatañazor
La iglesia de Nuestra Señora del Castillo ocupa un lugar preeminente dentro de los límites de la muralla de la localidad de Calatañazor, a $32 \mathrm{~km}$ al suroeste de Soria (Fig.1). El aislamiento que sufre esta comarca, alejada de grandes centros urbanos, ha facilitado que el edificio haya permanecido ajeno a intervenciones historicistas. No obstante, los añadidos que lucen sus muros evidencian su uso continuado hasta nuestros días y le proporcionan el aspecto de un edificio ecléctico, difícilmente clasificable dentro de los cánones clásicos manejados para los estilos artísticos arquitectónicos.

Tal y como la conocemos, la iglesia es un edificio de formas sobrias. Posee una planta rectangular con testero recto, engalanado al interior con un retablo renacentista y de nave única muy elevada, con fachada románica en el hastial occidental y coro de madera a los pies. Algunas estructuras flanquean su planta, como la torre cuadrangular situada en el ángulo noroeste y una serie de estancias adosadas al flanco sur, compuestas por baptisterio, sacristía y capilla en su extremo oriental.

Pocas son las referencias historiográficas que conservamos de este edificio, aunque fue objeto de estudio ya en el siglo XVIII, cuando Loperráez (1788: vol. XIII, p. 212) nos la refiere indicando "que mucha parte de ella es bastante antigua, y tiene el título de nuestra Señora del Castillo, y antes tuvo el de S. Salvador...". A partir del siglo XX aparecen someras descripciones de la iglesia centradas más en la tipología de sus elementos ornamentales que en el valor de sus estructuras arquitectónicas. Las dos primeras obras que se ocupan del edificio serán además referencia para los posteriores trabajos. Así, la guía artística de Taracena y Tudela (1928: p. 152) lo menciona centrándose en su fachada occidental, donde llama la atención sobre sus motivos ornamentales vegetales, a los que denomina como califales, y la composición de los tres arquillos ciegos bajo el rosetón baquetonado situado sobre la portada. Casi diez años después, Gaya (1946: p. 97) llama de nuevo la atención sobre la portada occidental, donde apunta que se conserva su fábrica más primitiva, de época románica, sin distinguir ningún tipo de diacronía en los elementos que la componen. Con más precisión relata los componentes decorativos de capiteles, arquivoltas y alfiz de dicha portada que, en su opinión, dotan al conjunto de "un aire francamente árabe".

También los estudios posteriores se centran en la misma fachada del templo, con referencias explícitas al trabajo de Gaya. Así lo hace García (1982 y 1986), quien no duda en adjudicar al edificio una cronología del siglo XII (1982: p. 102) por la pujanza alcanzada por esta localidad en dicha centuria, lugar de paso entre El Burgo de Osma y Soria. Ya en la década de los 90, Ruiz (1990: p. 575) trata de profundizar en la influencia que sobre la ornamentación de la iglesia ejerce el arte hispanomusulmán, a la par que insiste en introducir en el debate la recepción de fórmulas propias de los talleres silenses, ya comunes en todo el románico soriano. Para ello introduce paralelos tan dispares como el Castillo de Gormaz o la propia mezquita de Córdoba, edificios que garantizarían su raigambre andalusí con la aparición de 
ciertos rasgos como el alfiz o los arquillos lobulados en la portada principal (p. 580). No obstante, debe destacarse también en este trabajo la consideración de la fachada occidental como elemento reutilizado dentro de la fábrica gótica del edificio (p. 577).

El único autor que alude a una reforma del edificio en época moderna será Martínez (1980). Esta intervención, según señala, afectaría a toda la iglesia y solamente respeta el hastial occidental primitivo. La bóveda de terceletes de la capilla mayor, con los gruesos contrafuertes que la contrarrestan (p. 173), le sirven al mismo autor para dictaminar además una fase gótica avanzada para esta obra, aportando como cronología el primer cuarto del siglo XVI y adjudicando su patrocinio a la familia de los Padilla, señores de Calatañazor. El resto de nave y coro serían muy posteriores, correspondiendo al siglo XVIII.

A principios del siglo XXI se realiza un estudio de la iglesia, con motivo de la restauración llevada a cabo en sus cubiertas, en la que se plantea una evolución arquitectónico-constructiva ${ }^{1}$. En este estudio se llegan a diversas conclusiones de las que destacamos algunas de ellas. En primer lugar, consideran el muro de perfil convexo existente en dicha fachada como un elemento anterior al edificio, una espadaña prerrománica a la que posteriormente se le adosa la iglesia románica; en

1 Cobos Guerra, F.; García Leal, C. y Cobo Solano, V. 2001: Proyecto de obras de reparación de cubiertas y fábricas de la iglesia de Santa María del Castillo. Calatañazor (Soria), Memoria manuscrita depositada en el Servicio Territorial de Cultura de la Junta de Castilla y León. segundo lugar, la concepción de un templo medieval de planta tripartita, de acuerdo a la tipología basilical de la fachada; y por último, la conservación de todo el lateral sur y la esquina sureste de la iglesia original románica (incluyendo en dicha fase la capilla con cubierta de crucería en este ángulo. Fig. 2), la cual habría sobrevivido a la reforma de la cabecera en el siglo XVI.

\section{LA EVOLUCIÓN CONSTRUCTIVA DE LA IGLESIA}

Como hemos apuntado con anterioridad, gran parte de la iglesia que actualmente observamos en una primera aproximación a sus fábricas corresponde a una gran reforma realizada en época gótica avanzada. Sin embargo, la lectura de paramentos ha revelado distintas fases anteriores y posteriores. En total, nueve fases que configuran la evolución constructiva de la iglesia hasta nuestros días.

\section{Etapa I. Edificio originario y primera fase de época románica}

Los escasos testimonios del edificio originario aparecen repartidos en los muros norte, sur y oeste del aula (Fig. $3)$. Desde el punto de vista estratigráfico son elementos independientes aunque poseen características materiales que nos permiten interpretarlos como parte de una misma obra. La fábrica, de doble cara, fue realizada en sillería rectangular calcárea muy bien ajustada, que nos remite a un horizonte cronológico románico reforzado

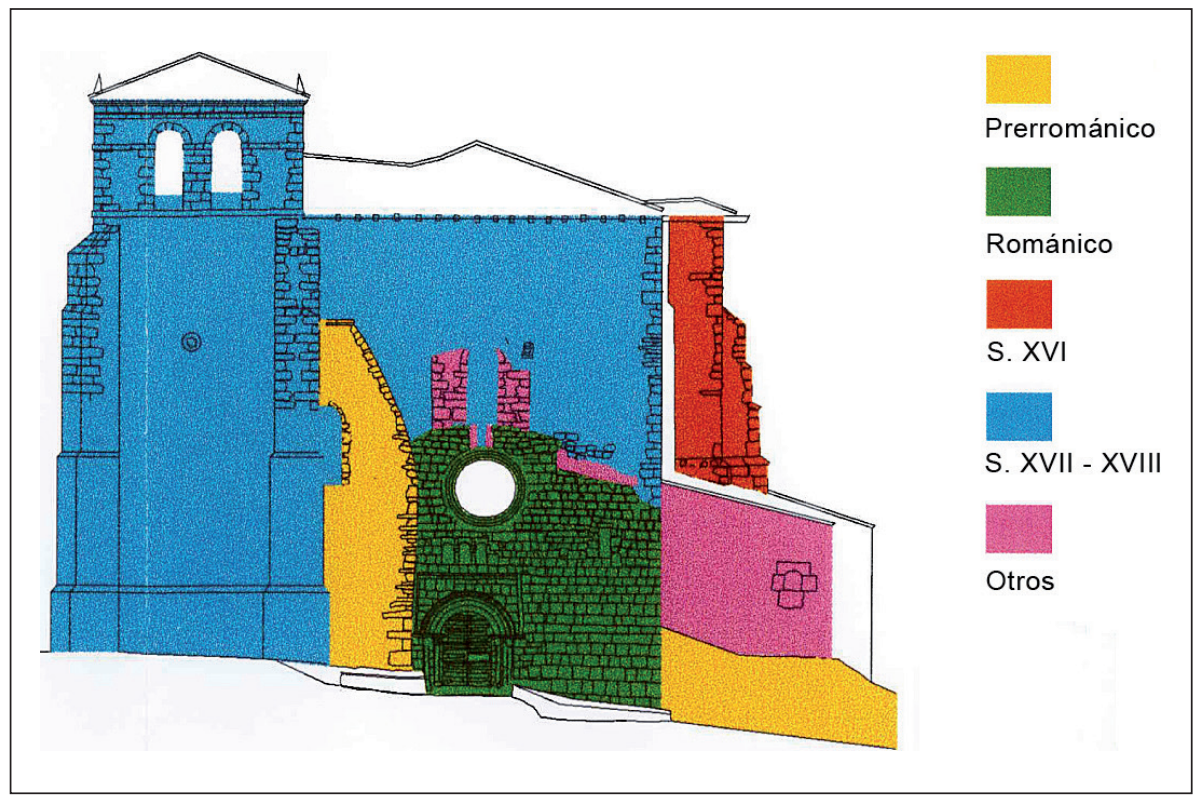

Fig. 2. "Lectura elemental de las fábricas" de la fachada occidental (Cobos 2001, citado supra en nota 1 ) 


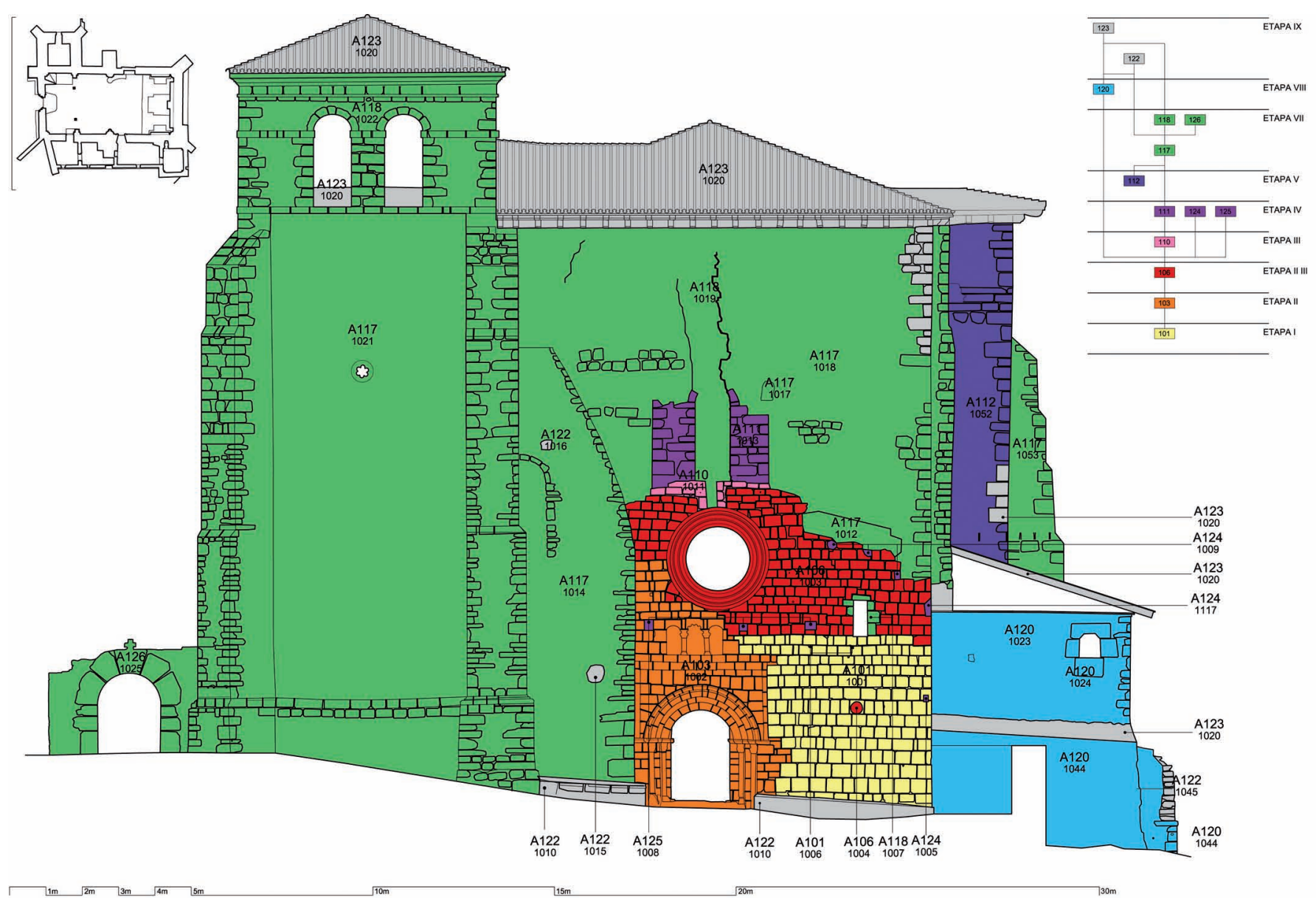

Fig. 3. Lectura de paramentos. Alzado fachada occidental

por el tipo de tallante empleado (a $45^{\circ}$ con hoja de aproximadamente $5 \mathrm{~cm}$ de anchura que deja una huella fina y ligeramente curvada) y la presencia de numerosas marcas de cantero: sencillas flechas, aspas, estrellas o triángulos, entre otras (Fig. 4).

En la fachada oeste del templo identificamos como de este período las primeras 14 hiladas de su lateral meridional, destacando en las inferiores una disposición a soga y tizón (A101, UE1001). Esta construcción se prolonga por el costado sur del templo sin proyección hacia occidente formando así el ángulo suroccidental de la construcción.

También en el costado sur de la iglesia y sin conexión física con la fachada oeste, a una distancia de 5 $\mathrm{m}$ y desplazado $90 \mathrm{~cm}$ hacia el sur, conservamos otro lienzo de similares características (A102, UE1082 y 1097). Sin embargo, en él podemos apreciar dos rasgos que hacen singular al edificio originario. En su extremo occidental se puede observar el ángulo de su esquina suroccidental de la construcción. Además, de todos los restos identificados para esta primera etapa, este es el único paño donde se observa parte de un estrecho contrafuerte.

El último de los muros localizados con las características comunes de esta primera etapa, se sitúa a 11 $\mathrm{m}$ del paño anterior, en la fachada norte. De todos los descritos, este lienzo es el que conserva mayor altura, alcanzando los 6,6 m (A102, UE1028 y 1122). Dos son las singularidades que apreciamos en esta fábrica. Al interior, en el segundo tramo de la actual nave, el muro se remata con una sencilla moldura en piedra con perfil de nacela, características propias del periodo románico. Probablemente corresponda con la altura sobre la que apoyaría una cubierta, aunque también pudo ser el nivel desde el que se alzase otro cuerpo constructivo. Además, el muro cuenta también con un acceso con arco de medio punto y rosca de jambas lisas, perfectamente integrado en su fábrica. Sin embargo no conservamos nada de su decoración, posteriormente modificada (A112). 


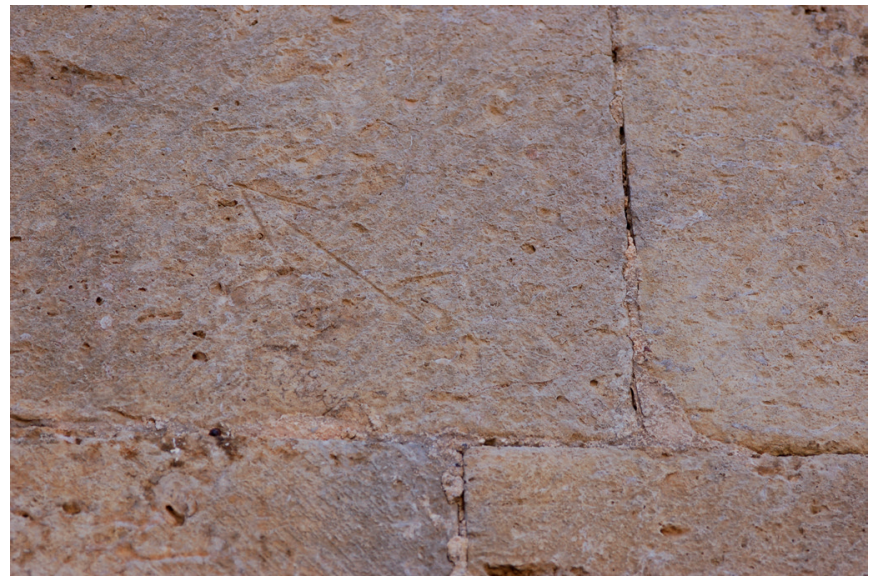

Fig. 4. Ejemplo de marca de cantero en la fábrica de la fachada occidental. Etapa I

La situación independiente de los tres paños aludidos en tres de las fachadas de este edificio, no permite defender desde el punto de vista estratigráfico su pertenencia a una misma estructura. Sin embargo, desde el punto de vista tipológico sí podemos relacionarlos entre sí. Las características de su fábrica, las alturas que conservan o el espacio que delimitan son argumentos suficientes como para defender su unidad constructiva, aunque no podamos aclarar cómo sería su límite occidental. En cualquier caso, es evidente la anterioridad al resto de estructuras que conforman la iglesia actual, función que no tiene por qué determinar la originaria. $\mathrm{Y}$ a pesar de las pocas evidencias que venimos observando, también podemos aportar algunas hipótesis sobre su cubierta, dado que el tipo de contrarrestos empleados nos permite suponer la utilización de una cubierta de madera.

$\mathrm{Ni}$ las características materiales ni las noticias acerca de Calatañazor en estos siglos ayudan a definir mejor la edificación documentada, si bien el hecho de que una de las parroquias de la ciudad de Soria, tras otorgársele fueros en época de Alfonso VIII (1155-1214), estuviera poblada por gentes procedentes de este emplazamiento (García 1982: p. 57; Martínez 1984: p. 20) es garantía para suponer la presencia de una población estable aquí desde la primera mitad del siglo XII.

\section{Etapa II. Alteración de la fábrica original en época románica}

En un segundo momento constructivo, el edificio originario recibirá una serie de transformaciones con claros signos de reempleo de materiales en sus fábricas. La sillería que se utiliza en estos momentos, presenta las aristas escantilladas, disponiéndose mayoritariamente a soga con algún tizón intercalado. Este hecho implica la

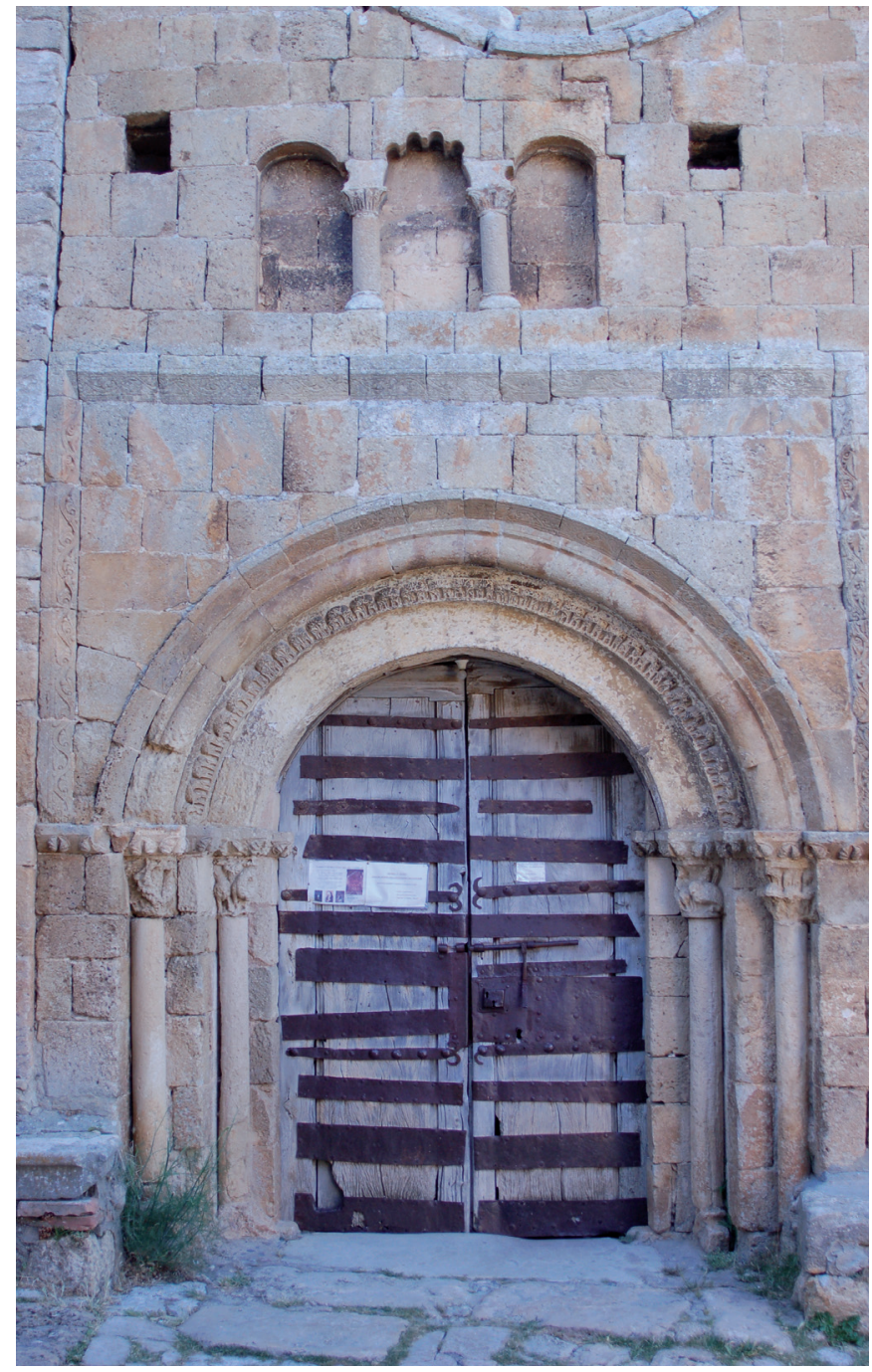

Fig. 5. Portada fachada occidental. Etapa II

realización de hiladas algo más sinuosas, lo que provoca la utilización de codos para regularizar hiladas y cuñas de madera o piedra para ajustar los sillares. Además, también se observan pequeñas diferencias en cuanto al tipo de material empleado puesto que el calcáreo se acompaña ahora con alguna piedra toba.

Dos son las zonas del edificio donde identificamos este tipo de fábrica. En la fachada de poniente (A103, UE1002) se construye una portada, que incluye en su obra los paramentos aledaños y una pequeña arquería triple situada sobre ella (Fig. 5). Dicha portada posee una puerta abocinada que queda enmarcada en un alfiz con moldura ornamentada, utilizando una doble técnica decorativa, incisa y en bajorrelieve. El arco de entrada es ligeramente apuntado como las dos arquivoltas (la interior decorada con motivos fitomórficos y la exterior de baquetón simple) y el guardapolvo que lo enmarca. La 


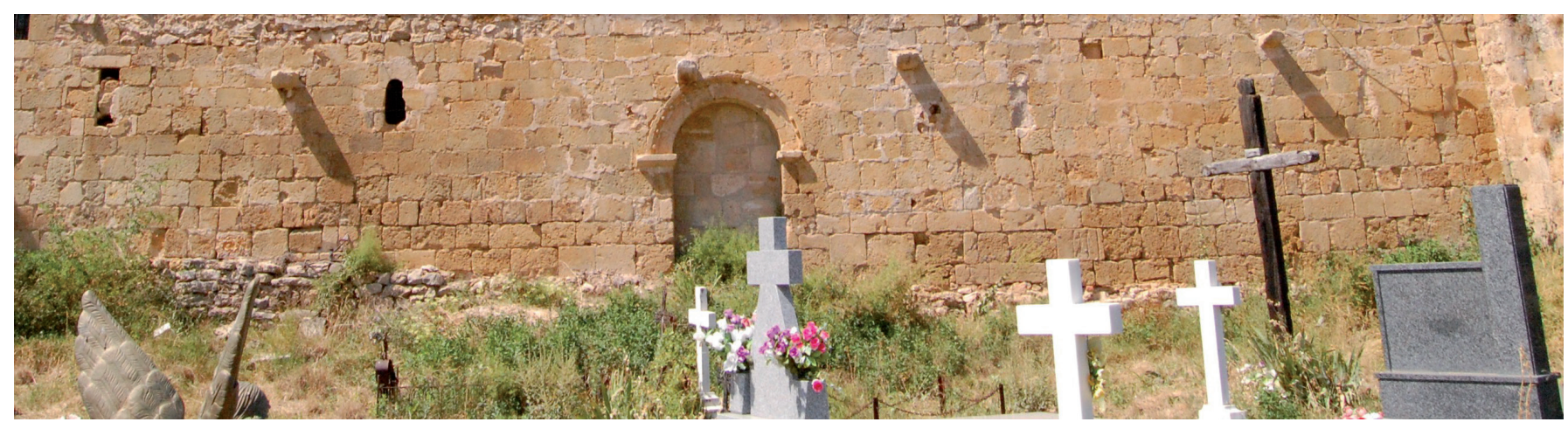

Fig. 6. Vista panorámica de la parte baja de la ampliación meridional

degradación sufrida por la portada en columnas y capiteles apenas deja observar en estos últimos la decoración figurada y vegetal de sus cestas. De los tres arquillos ciegos construidos sobre ella el central es polilobulado y los laterales de medio punto rebajados trasdosados y con decoración de perlado. Sin embargo, esta pequeña arquería también presenta síntomas de reutilización entre las piezas que la componen puesto que ofrece desviaciones en las columnillas, los salmeres sobre sus capiteles están intercambiados y los arcos laterales están interrumpidos en su desarrollo.

La otra zona del templo donde identificamos este tipo de fábrica es en el costado sur, donde se añade una estancia (Fig. 6) cuyo nivel de uso quedó por debajo del que conocemos para la nave principal (A105, UE1037) ${ }^{2}$. De una única planta, este espacio posee una portada en su muro meridional flanqueada por tres ventanas de las cuales, la más próxima a la puerta por su lado este conserva un dintel trasdosado con decoración de perlado enmarcada muy similar a la situada en la triple arquería ciega sobre la portada occidental. El acceso posee cierta monumentalidad, puesto que está adornado con un guardapolvo con bolas apeado sobre impostas de nacela. $\mathrm{Su}$ parte superior es recorrida por una hilada horizontal compuesta por seis ménsulas, sobre la cual se colocaría el durmiente de la cubierta de madera de un pórtico.

En los dos casos observados se sigue construyendo con fórmulas que se mueven dentro de los cánones románicos y su posición estratigráfica nos permite situarlo cronológicamente en un siglo XII avanzado (García 2012: p. 121). Sin embargo, cuestiones tales como la procedencia del material reutilizado, del que nos sabemos si formaba parte del edificio originario, y la función

\footnotetext{
2 La ampliación meridional puede ser puesta en relación con la llamada "claustra" que cita la documentación de época moderna (ADO-S, Libro 96/38, f. 6r-v. 1606, noviembre, 20).
}

de la ampliación meridional, sin utilidad clara desde el punto de vista litúrgico, quedan ahora abiertas.

\section{Etapa II/III. Nueva fachada occidental. Transición del Románico al Gótico}

La fachada occidental es nuevamente transformada en altura con la construcción de un paño que se desarrolla desde la esquina suroeste del edificio actual hacia el Norte, donde ha sido alterado por adiciones posteriores. Sobre la portada se eleva un cuerpo a mayor altura en el que se inserta un gran óculo (A106, UE1003. Fig. 7). Esta composición, que parece corresponder a la división tripartita de la fachada de un edificio basilical, conserva en su ángulo superior meridional un canecillo figurado, que igualmente nos está indicando el lugar sobre el que apoyaría uno de los aleros de esta nueva edificación.

$\mathrm{Su}$ fábrica, presenta una sillería de módulo menor con predominio de sogas que forman hiladas sinuosas en las que observamos cierto escalonamiento. La presencia del óculo, abocinado mediante dos arquivoltas boceladas y con guardapolvo, provoca que las hiladas no guarden horizontalidad al aproximarse a él, inclinándose. El propio rosetón presenta una forma más próxima al óvalo que al círculo, aunque no creemos que se deba a que sus elementos hayan sido reutilizados, sino más bien a la adecuación a la obra precedente y cierta falta de experiencia en la fabricación de este tipo de elementos.

Además de las relaciones estratigráficas, las variantes tipológicas observadas lo sitúan en un momento de transición entre el Románico y el Gótico. Su léxico reinterpreta formas ya conocidas, plasmadas en la traza del aula y en la presencia de canecillos, e incorpora de manera titubeante otras de cronología más avanzada, como el óculo. 


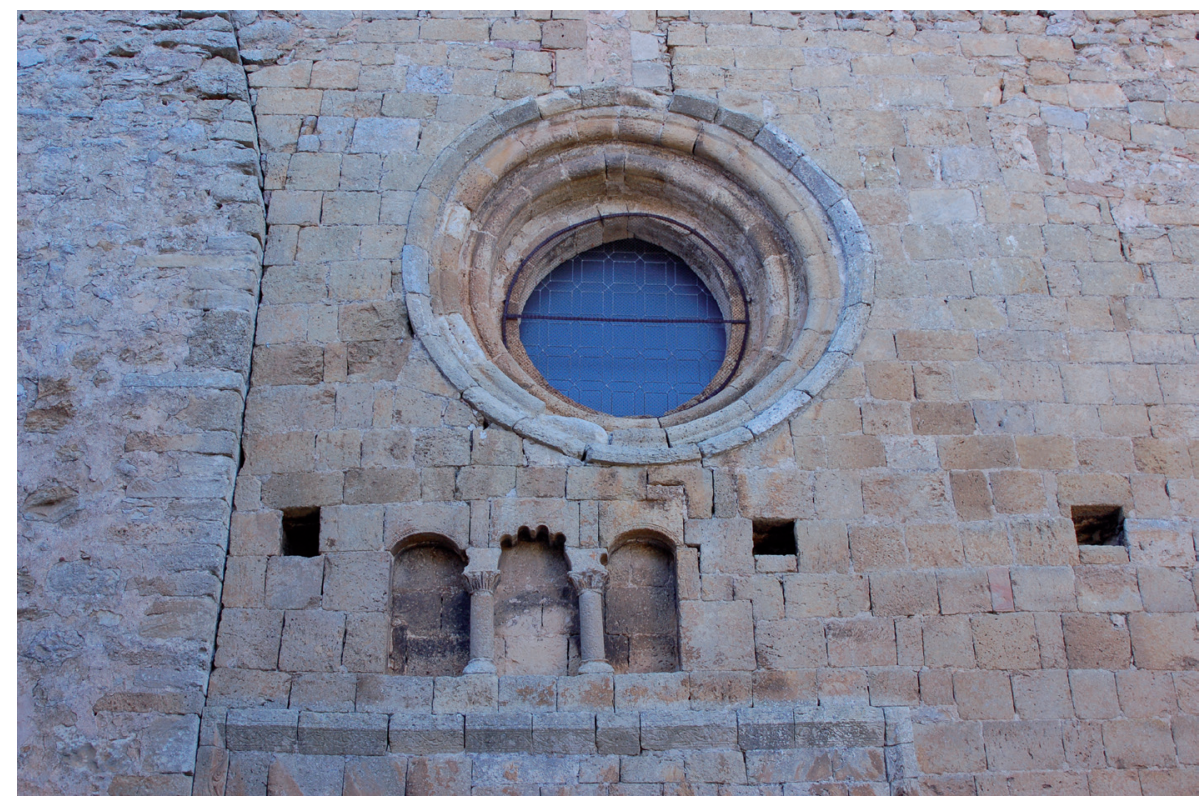

Fig. 7. Óculo en fachada occidental

\section{Etapa III. Construcción de una primera iglesia Gótica}

El análisis estratigráfico nos ha deparado la identificación de un edificio del que hasta ahora no se tenía noticia alguna, realizándose en este período su primera gran remodelación. Es ahora cuando contamos por primera vez con referencias sobre la delimitación oriental del templo (Fig. 8).

Comenzamos la descripción de esta remodelación del edificio en la fachada sur. Aquí, el muro meridional del aula es ampliado en altura con fábrica de sillería reutilizada probablemente de etapas anteriores, a tenor del módulo y talla empleado, tipo de marcas de cantero y su aspecto escantillado (A107, UE1098 y 1101. Fig. 9).

Avanzando hacia Occidente, la construcción enlaza los muros de fachada con un lienzo realizado en mampostería con predomino de material de toba y rematado con canecillos de nacela (A109, UE1091 y 1095). En él se construye una aspillera adintelada formada por sillares a la que se enfrenta, abriéndola en el muro que delimita la claustra, otra pequeña ventana adintelada (A109, UE1039). El objetivo de la construcción de este nuevo juego de ventanas es el de iluminar mejor dicho espacio, que ahora funciona como baptisterio.

En el otro extremo, hacia oriente, la nueva construcción sobrepasa a la originaria y conforma un ángulo constructivo (A107, UE1051) con un recio estribo sobre una potente plataforma que permite salvar el fuerte desnivel del terreno en este punto. El tramo ampliado incluye una ventana ojival abocinada que, combinada con otras ventanas adinteladas en una reforma posterior, nos sitúa en un horizonte cronológico distinto a etapas anteriores. No obstante, la presencia de una cornisa sostenida por canecillos de perfil convexo totalmente lisos, es síntoma de que aún nos encontramos ante un taller escultórico próximo a la tradición románica.

Sobre este nuevo tramo oriental situado en la fachada sur del edificio, se construye una capilla exterior de planta cuadrada (A108, UE1049) configurada de la misma forma, aunque añadiendo elementos nuevos. La fábrica de sus muros se realiza en un tipo de sillería que deja juntas muy gruesas entre las que se introducen cuñas que dan regularidad a las hiladas. Sobre ellos se sitúan canecillos que configuran el alero de la cubierta, realizados con material reutilizado de un edificio más antiguo y, alguno de ellos, con decoración. Toda la estructura queda cubierta con una bóveda de crucería de nervios con sección cóncavo/convexa y clave posiblemente decorada, realizada íntegramente con piedra toba. Pese a que los argumentos estratigráficos quedan ocultos en la cara interior de sus muros, totalmente enlucidos, y su observación al exterior es imposible por lo escarpado del terreno, tanto su fábrica como la tipología de su bóveda nos ayudan a situarla en esta etapa.

Con todo lo dicho, la obra que hemos definido en esta etapa nos descubre una nueva construcción hasta la fecha ignorada por la historiografía. Esta intervención cambió profundamente la fisonomía original del edificio, del que ahora conocemos cómo pudo ser su cabecera. Y considerando la posición dentro de la secuencia del templo y las características de sus elementos singulares 


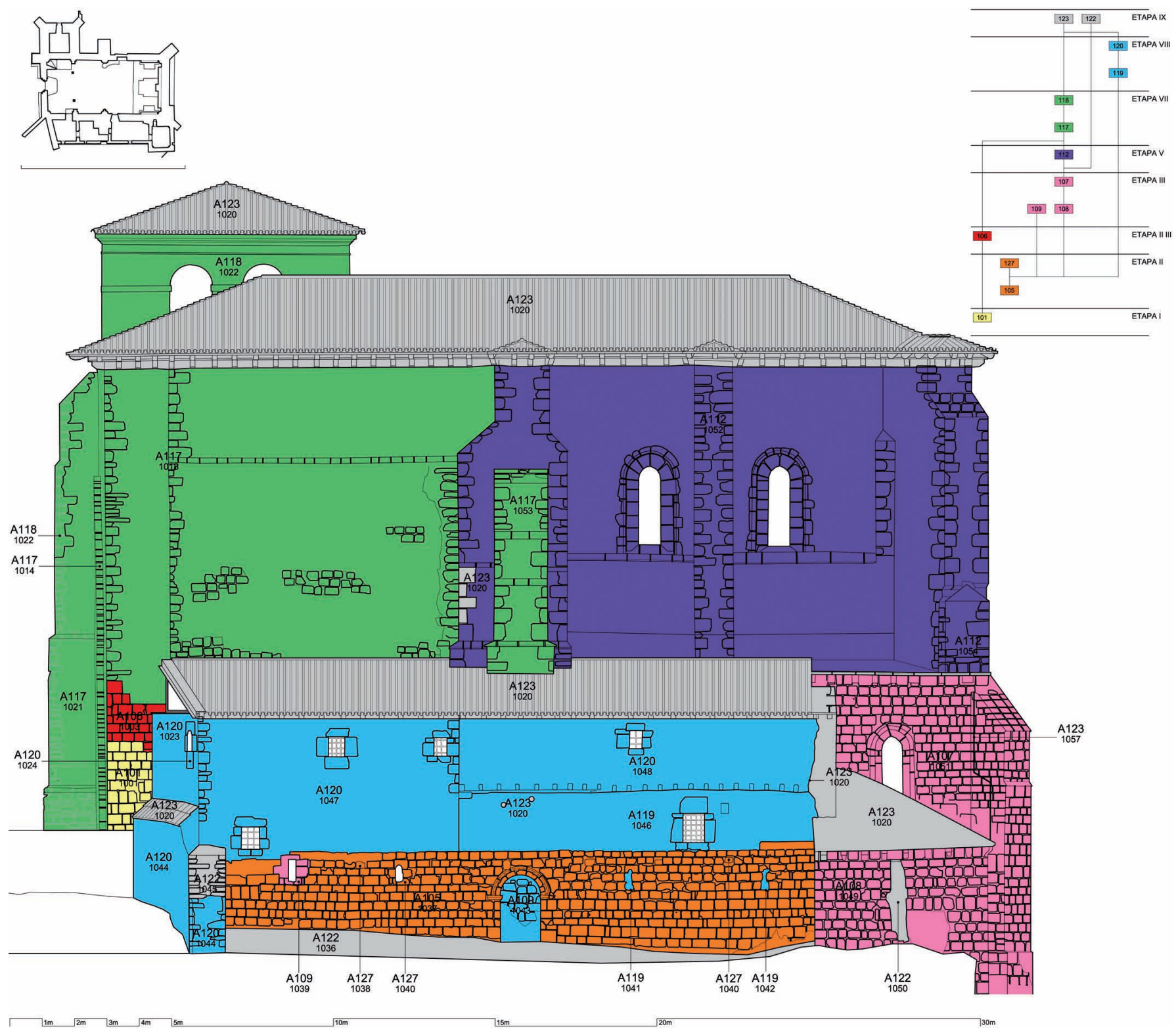

Fig. 8. Lectura de paramentos. Alzado meridional

(vanos, bóveda de crucería, canecillos, etc.), de arcaicos rasgos góticos, debemos situar esta intervención a lo largo del siglo XIV.

\section{Etapa IV. Nuevas adiciones en la fachada occidental}

De forma inmediata, dada la tipología y, sobre todo, la situación estratigráfica de los elementos que nos ocupan, se llevan a cabo una serie de pequeñas intervenciones en la portada principal del templo. En el hastial occidental, coronando el tímpano triangular del paño central de la fachada románica, se construyó una pequeña espadaña (A111, UE1013) que posee un único vano apuntado.
También es en este momento cuando se proyecta la construcción de un pórtico (A125, UE1008 y 1009) a modo de nártex para cobijar la parte central de la fachada occidental. La única evidencia con la que contamos para dar testimonio de este elemento es la presencia de una línea horizontal de tres agujeros rectangulares que cortan distintos lienzos de las etapas II y III y que recibiría la estructura de la cubierta de dicho atrio hoy desaparecido. Esta estructura quedaría centrada con la portada aunque desconocemos la anchura que llegó a alcanzar hacia su lateral septentrional, donde se producen reformas posteriores.

Estas pequeñas intervenciones las consideramos claves para poder recomponer la fisonomía que poseía 


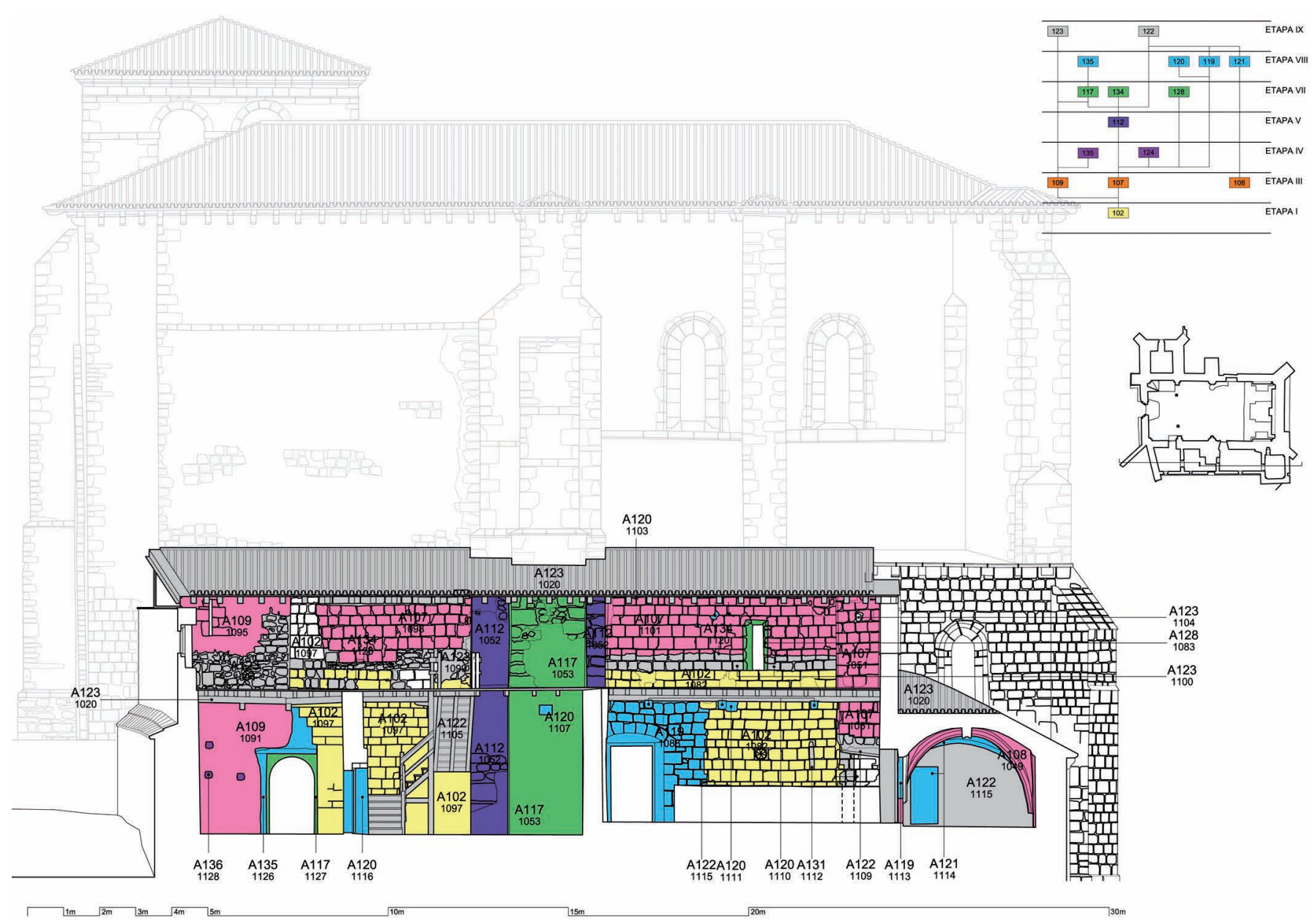

Fig. 9. Lectura de paramentos. Sección septentrional de la ampliación meridional

la iglesia medieval de Santa María. Por un lado, la construcción de la espadaña sugiere que esta iglesia no tenía torre durante este período. Por otro lado, El pórtico protegía su entrada principal y su posterior desaparición debió coincidir con las adiciones modernas.

\section{Etapa V. El comienzo de la gran transformación gótica del templo en el siglo XVI}

El recorrido medieval de la iglesia de Santa María acaba con una extraordinaria alteración de su fisonomía que la historiografía concede al patrocinio del linaje de los Padilla, señores de Calatañazor, durante el primer cuarto del siglo XVI (Martínez 1980: p. 173).

Es en esta etapa cuando el aula del templo adquiere su altura definitiva. El extremo oriental románico queda totalmente desmantelado y sobre los restos conservados del aula se elevan sus nuevas fábricas que, con un testero recto, alcanzan aproximadamente los diecinueve metros de altura (A112, UE1029 y 1052). Esta construcción, dividida en dos grandes tramos, se diseña para ser cubierta con un sistema abovedado de crucería plenamente gótico (A112, UE1072). El grueso de esta intervención se centra en generar un nuevo espacio capaz de acoger en su interior un retablo de grandes dimensiones (Fig 10).

La proyección de altos y gruesos contrafuertes capaces de soportar el empuje de los nuevos paramentos y bóvedas proporcionan al templo el aspecto 'abaluartado' que hoy le caracteriza. (Fig. 11). Su función condiciona su tipología, más gruesos los contrafuertes situados en los ángulos, que recogen los empujes de todos los nervios de la bóveda, frente a los ubicados en el centro de los paños. A medida que se eleva la construcción sus elementos van perdiendo anchura y esta circunstancia se resuelve articulando los paños de fachada en tres 'calles' horizontales con impostas biseladas intermedias y rematando los escalones de los estribos con una especie de 


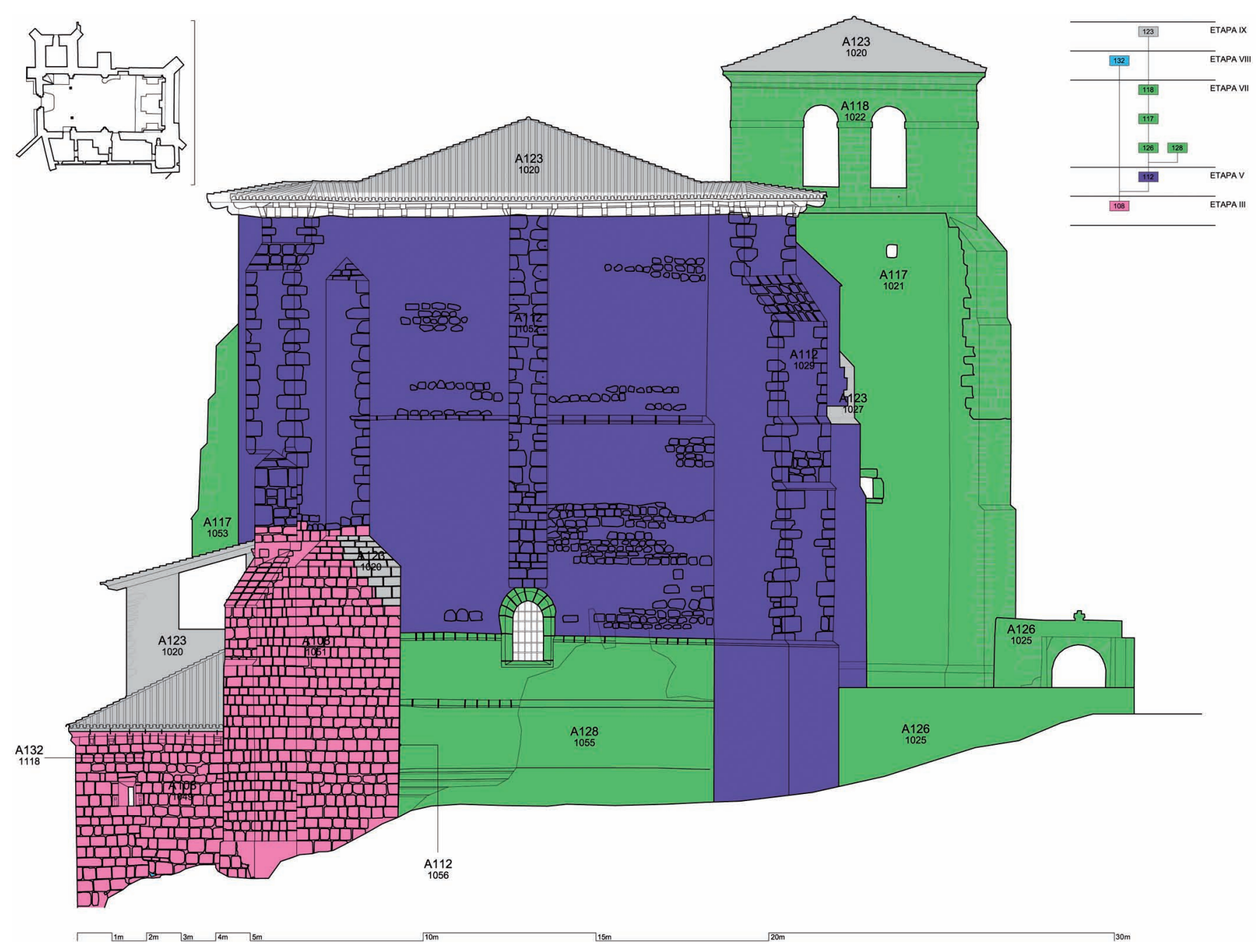

Fig. 10. Lectura de paramentos. Alzado fachada oriental

vierteaguas. En la "calle" superior de los paños laterales se abren dos vanos ojivales y abocinados mediante una arquivolta baquetonada y moldura interior cóncava.

La única estructura que rompe la simetría entre ambos flancos de la obra gótica en la cabecera es la instalación de un contrafuerte prismático en el ángulo suroriental del templo (A112, UE1054), reforzando la parte más inestable del mismo provocada por la topografía del terreno sobre el cual se asienta.

Pese a que esta actuación posee cierta heterogeneidad material, la tipología de sus elementos singulares (ventanas y contrafuertes) y la confirmada coetaneidad estratigráfica fueron argumentos suficientes para garantizar su pertenencia a esta misma etapa de elementos puramente góticos. Los muros de doble hoja de sillería combinan grandes bloques de mampostería al exterior de las fachadas este y sur, donde la sillería se reserva para los encadenados en las esquinas de los contrafuertes (A112, UE1052).
La transformación del primer tramo de la nave y el presbiterio lleva asociada la alteración de sus accesos laterales. Parece que fue en estos momentos cuando se ciega la puerta románica del costado septentrional y se convierte parte de su vano en un simple nicho. Lo interesante es que al interior el muro de cierre de este acceso es coetáneo a la construcción del arcosolio gótico (A112, UE1074), pues las piezas que lo componen forman parte, igualmente, de la decoración del extradós del arco. Interpretamos que en estos momentos es cuando se desmonta la capilla existente en esta fachada, documentada por medio de la excavación arqueológica de esta zona y que, sin embargo, atribuye a esta reforma gótica su construcción ${ }^{3}$.

\footnotetext{
3 Hervás, M. A. y Retuerce, M. 2004. Informe previo de la intervención arqueológica en la necrópolis medieval de la iglesia de Santa María del Castillo (Calatañazor, Soria), en relación con la restauración de la misma
} por la Consejería de Fomento. Informe manuscrito, p. 3. 


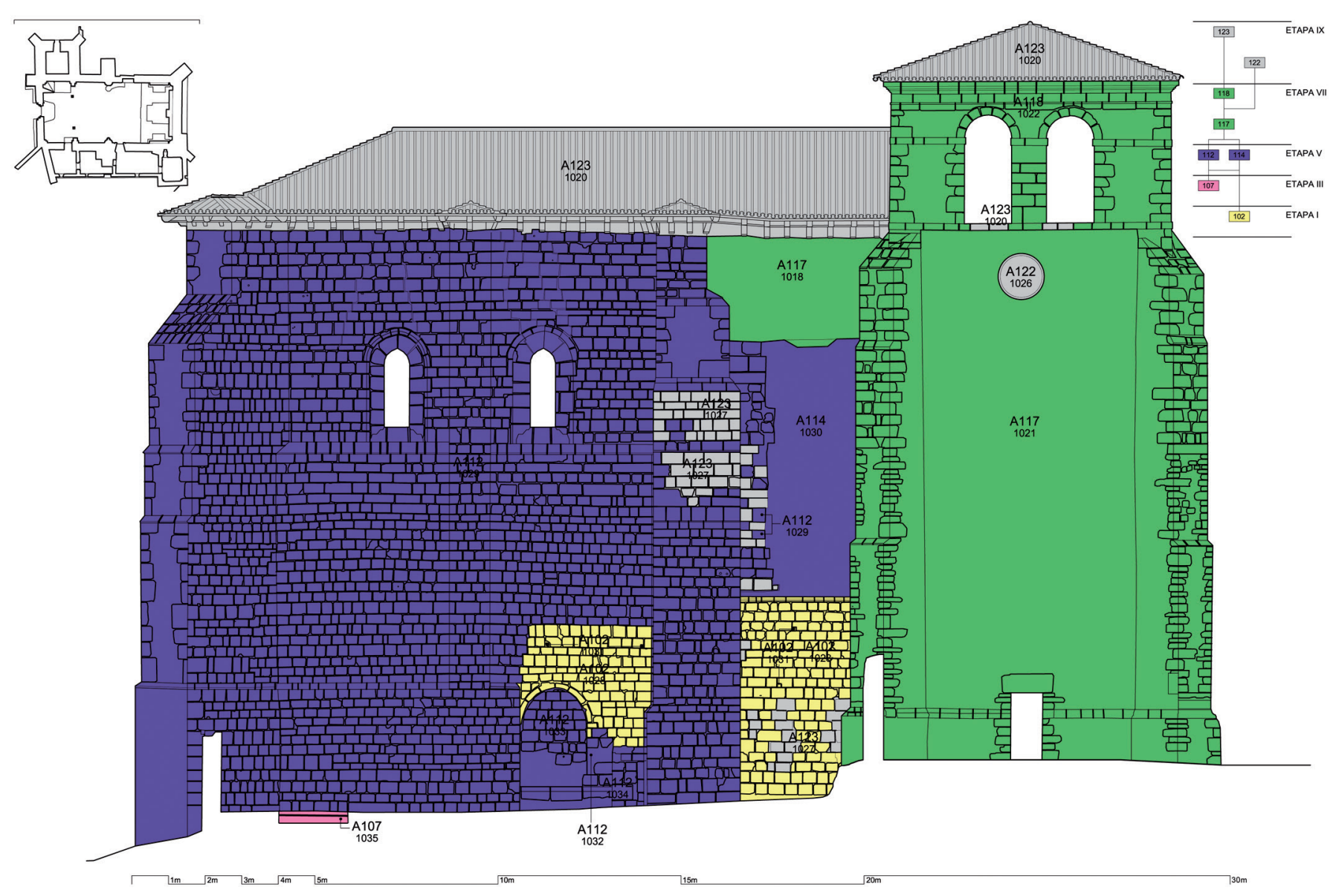

Fig. 11. Lectura de paramentos. Alzado fachada septentrional

Al interior, destaca por su morfología la cubierta de la capilla mayor (Fig. 12), con una bóveda nervada compuesta por arcos cruceros y terceletes curvos que se disponen formando una figura tremolada, decorada con pinjantes (hoy perdidos). La tipología de esta bóveda, sumada a los pilares compuestos del interior de los lienzos y a la imposta que los recorre (A112, UE1072), forman un conjunto homogéneo que permite validar la cronología del siglo XVI propuesta por la tradición historiográfica (Martínez 1980: p. 173).

Por último, quedaría definir cómo se llevó a cabo esta gran reforma a los pies del edificio. En la esquina noroccidental, entre el contrafuerte occidental del muro norte y la torre posterior identificamos un muro (A114, UE1030) sobre la imposta románica, construido con material reutilizado de acarreo (mampuestos de tamaño medio, sillares, ladrillos e incluso piezas decoradas), que nada tiene que ver con la factura de los lienzos anteriores (Fig. 13). Sin embargo, sus relaciones estratigráficas lo sitúan en este mismo momento, ya que es posterior al edificio románico y anterior a la ampliación de la etapa moderna. La precariedad que presenta es indicio de una solución de emergencia que pretende cerrar el espacio del aula conectándolo con la fachada existente. No podemos determinar los motivos que llevan a realizar esta obra, pero, a tenor de la forma de este muro, parece claro que la obra gótica quedó interrumpida de manera precipitada.

Así pues, la presencia de todas estas novedades supone asumir un cambio de escala y proporción hasta entonces condicionada por un ambiente cultural y litúrgico guiado estrictamente por las formas medievales/ románicas. Esta variación de la iglesia de Santa María debe ser interpretada como reflejo de un nuevo contexto social en el que se ha querido ver la intervención directa de la familia de los Padilla, señores de Calatañazor en estos momentos (Martínez 1980: p. 173). Por lo tanto, también se debe a este proyecto el desmonte de la capilla norte, posiblemente de función cementerial y vinculada a un personaje ajeno a este linaje. El arcosolio que sustituye a su acceso podría albergar un sepulcro que sirviera para hacer ostentación de su patrocinio. 


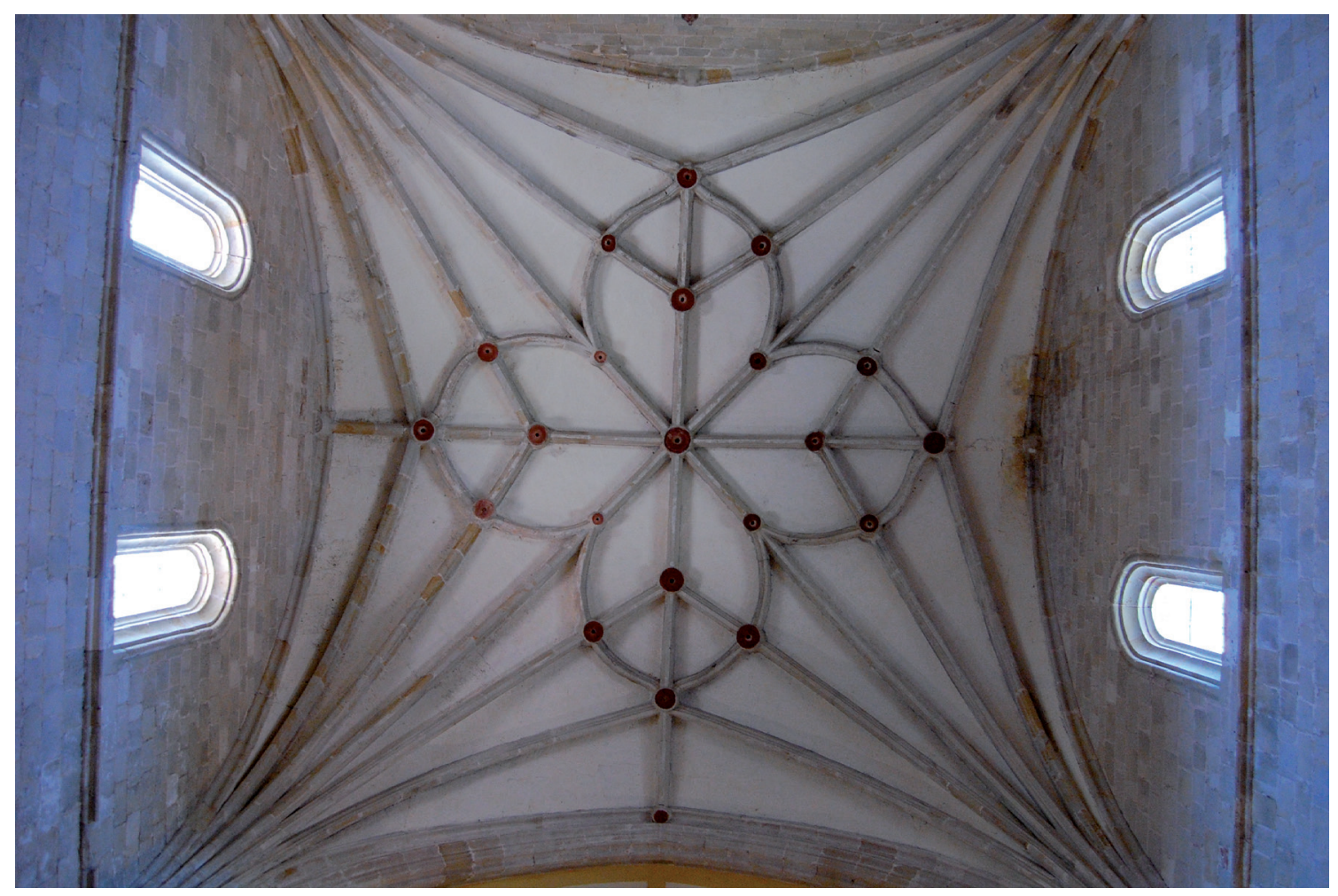

Fig. 12. Bóveda compuesta de arcos cruceros y terceletes en Capilla Mayor

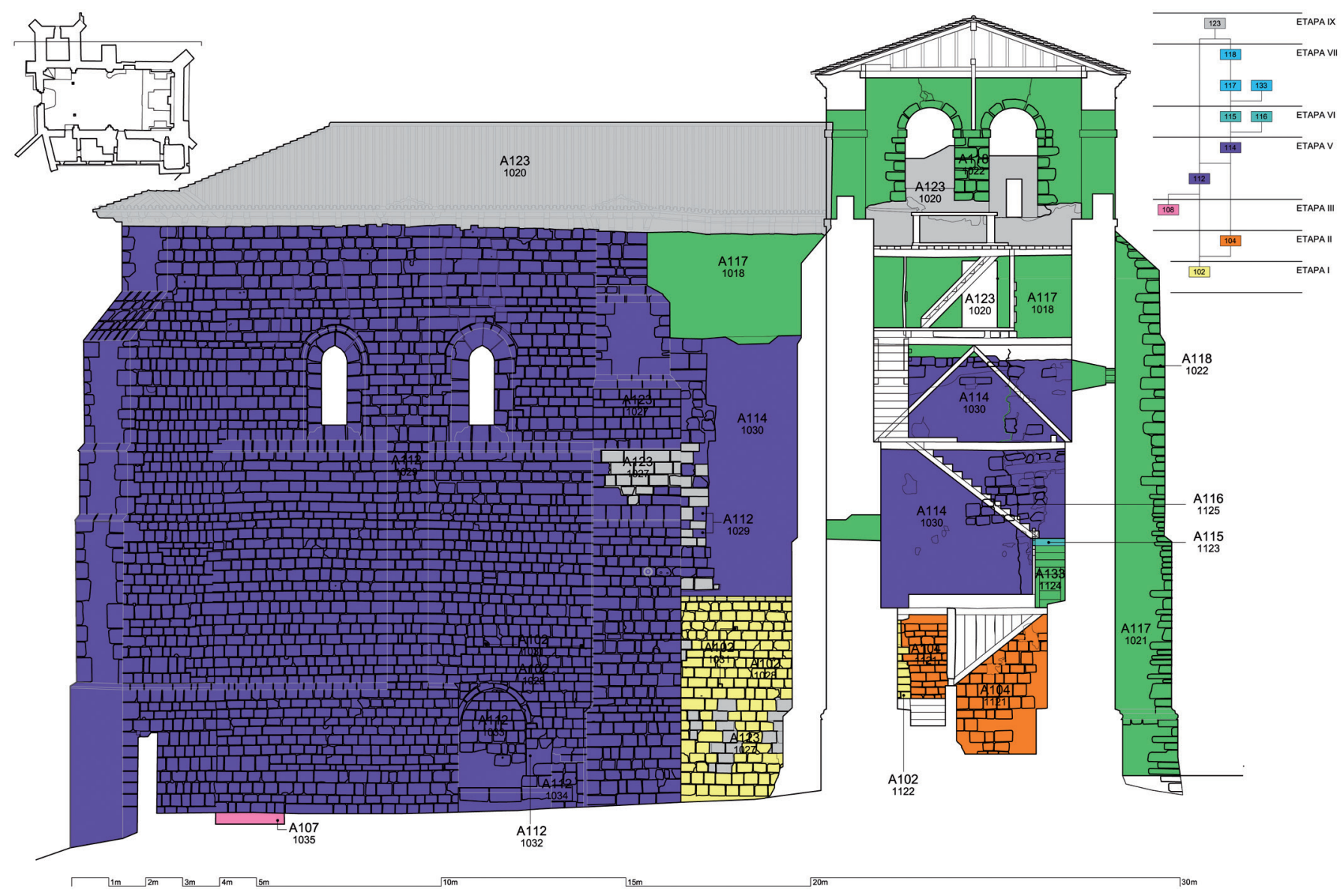

Fig. 13. Lectura de paramentos. Alzado septentrional y sección meridional de la torre 


\section{Etapa VI. Reformas de un edificio inacabado}

El muro de cierre de carácter provisional anteriormente aludido (Etapa V. A114, UE1030), es horadado para construir en él una puerta con dintel de madera (A115, UE1123). Su posición coincide con un rellano de la escalera actual de ascenso al campanario de la torre, sin embargo da paso a un nivel interior del aula que no coincide con la actual plataforma del coro. Por ello, nos preguntamos si hubo un coro anterior en una posición diferente, sin embargo no contamos con referencias materiales que nos ayuden en esta cuestión.

Por otro lado, en este mismo muro se origina una grieta vertical (A116, UE1125), que no aparece en los elementos precedentes ni posteriores a su construcción. El hecho de que la grieta se sitúe en este lugar y que no se extienda a otros elementos diacrónicos con el lienzo parece suficientemente importante como para mencionarlos de cara a la problemática que afecta a la siguiente etapa.

\section{Etapa VII. Conclusión de la gran transformación en Época Moderna}

La gran transformación del aula de la iglesia de Nuestra Señora del Castillo, que comienza en época gótica (Etapa V), es concluida a continuación por medio de la construcción de su tramo occidental y una torre. Como ya dijimos en su lugar correspondiente, el proyecto gótico no llegó a terminarse, cerrando el edificio de manera precipitada. Será ahora cuando se retome y finalice.

La nueva edificación elevará todos los muros perimetrales del aula a la misma altura, alcanzando la cota fijada en el proyecto del siglo XVI. La obra, que arranca sobre bancadas de regularización (A117, UE1012), se realiza combinando bancos de mampostería de diferente dimensiones y tipo de material que encadena en sus esquinas sillería de diferentes características (A117, UE1018). Además, se observan algunas piezas singulares reutilizadas (A117, UE1017) que, unidas al conjunto, otorgan a la obra un pobre aspecto que es enlucido al interior. Reconocemos el mismo aparejo en el nuevo estribo (A117, UE1053) adosado sobre el contrafuerte central del muro sur, el cual es así reforzado ante eventuales problemas de estabilidad.

Es en este momento cuando situamos la construcción de la torre existente sobre el extremo occidental de la fachada norte puesto que su fábrica tiene similares características a las que aludimos para los elementos anteriores. Además de la tipología de su fábrica, la documentación consultada confirma que en el año

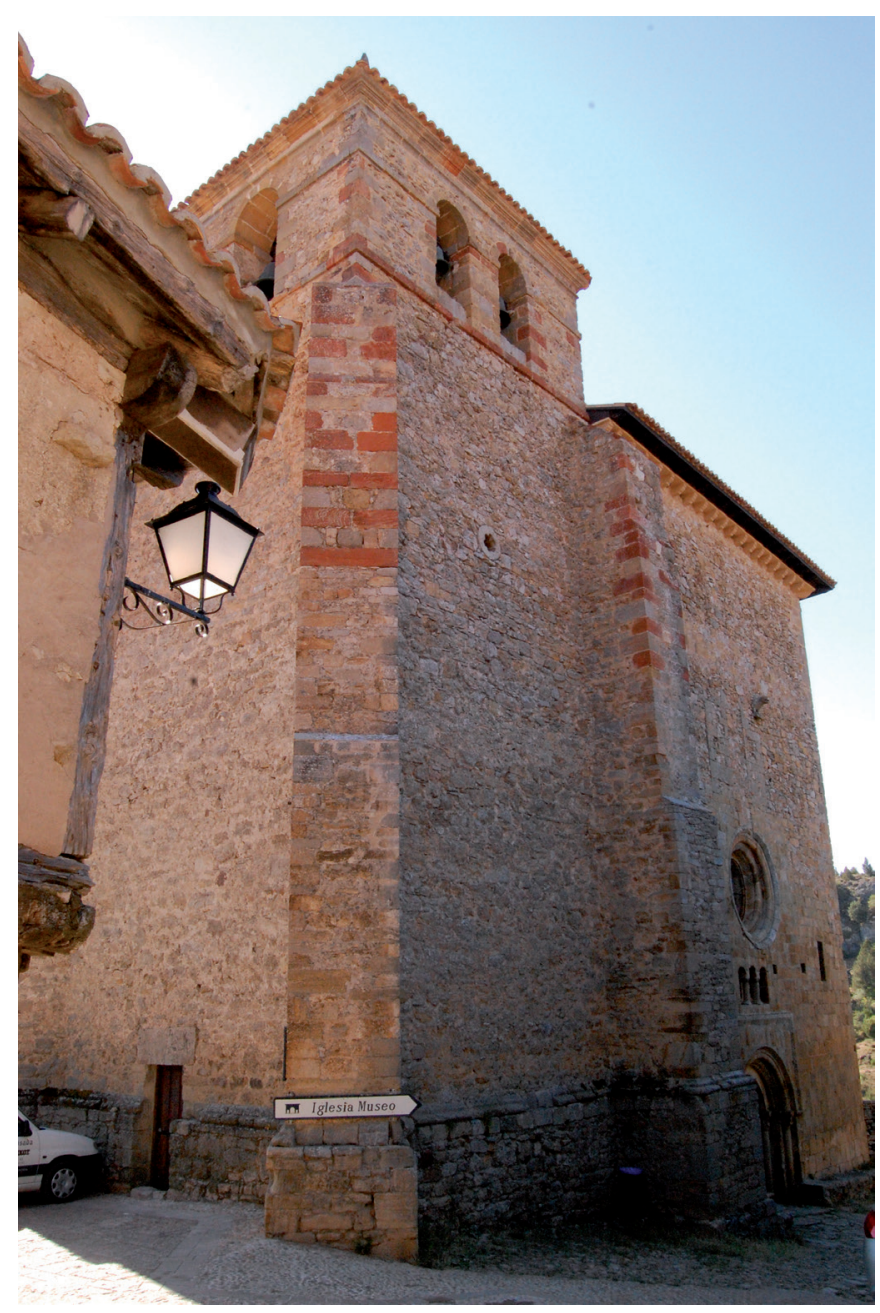

Fig. 14. Torre en el ángulo noroccidental de la iglesia de Nuestra Señora del Castillo

1688 el obispo del Burgo de Osma observó, y puso por escrito, que lo que más falta le hacía a esta iglesia era un campanario, por lo que la construcción de la torre se puso en marcha de inmediato ${ }^{4}$ (Fig. 14). Posee planta cuadrada y dos cuerpos que han llegado hasta nuestros días. El inferior (A117, UE1021), con una fábrica que continúa lo ya expresado anteriormente para esta etapa, y que en su fachada de poniente cuenta con un óculo hexapétalo, alcanza en altura la línea actual de cornisa del templo y está reforzado en sus esquinas con contrafuertes. Sin embargo, en los muros y los estribos del cuerpo superior se emplearon sillares en sus ángulos al igual que en el jambaje de las troneras de campanas, organizadas por parejas en cada paño. Estas características nos han hecho sospechar cierta falta de sincronía entre el cuerpo superior y el inferior que no éramos capaces de

\footnotetext{
4 ADO-S, Libro 96/40, f. 92v. 1668, octubre, 24
} 
demostrar estratigráficamente ${ }^{5}$. Sin embargo, la presencia en el alero norte de una inscripción que menciona al maestro de obras, Francisco del Molino, y el año de 1679 como el de finalización de las mismas, nos ha permitido abandonar esta hipótesis confirmando su unidad constructiva.

La tipología de todos los contrafuertes de la torre es la misma salvo la del situado en su esquina suroccidental (A117, UE1014) con un remate convexo y un aparente vano ciego de medio punto. Pero su singularidad no acaba aquí puesto que, además, su desarrollo se realiza hacia el sur invadiendo el tercio septentrional de la fachada occidental del templo. Estas características han sido interpretadas por los redactores del proyecto para su reciente restauración ${ }^{6}$ como propias de una espadaña, que sería anterior a toda la secuencia de etapas expuesta hasta aquí, y por lo tanto de cronología prerrománica (Fig. 15). Sin embargo, este singular elemento presenta una fábrica de mampostería con esquina de piezas encadenadas similares a la empleada en el cuerpo inferior de la torre, con la que estratigráficamente constituye una construcción solidaria. Para su edificación, observamos que los elementos pétreos colindantes de las etapas II y III, y que forman parte de la fachada actual, fueron desmantelados hasta el eje vertical exterior del marco septentrional del alfiz de la portada, el cual es respetado. Esta acción supuso la rotura, aún evidente, de las aristas de todas las molduras y sillares afectados, demostrando así la posterioridad constructiva de este discutido elemento. Igualmente, no podemos interpretar como vano de campana el arco ciego ubicado en la zona superior de su fábrica por un doble motivo. Por un lado, carece de alféizar y, por otro, el material que lo condena es similar al resto de su fábrica. Estos argumentos nos hacen pensar que dicho elemento forma parte de su propio proceso constructivo, quizá un vano de obra, que fue cegado a medida que esta era concluida. Las diferencias formales con el resto de contrafuertes de la torre se puedan explicar por su función de contrarresto, que junto al estribo adosado sobre el contrafuerte central de la fachada meridional en esta etapa, persiguen equilibrar la edificación frente al declive del terreno natural donde se documenta la aparición de grietas verticales abiertas en etapas precedentes (Etapa VI. A116, UE1125).

\footnotetext{
5 Idea que además encontraba su apoyo en la referencia del año 1770 en la que se echaba de menos el remate de la torre (ADO-S, Libro 96/53, pliego suelto. 1770, junio, 10. Cabrejas del Pinar).

6 Ver nota 1.
}

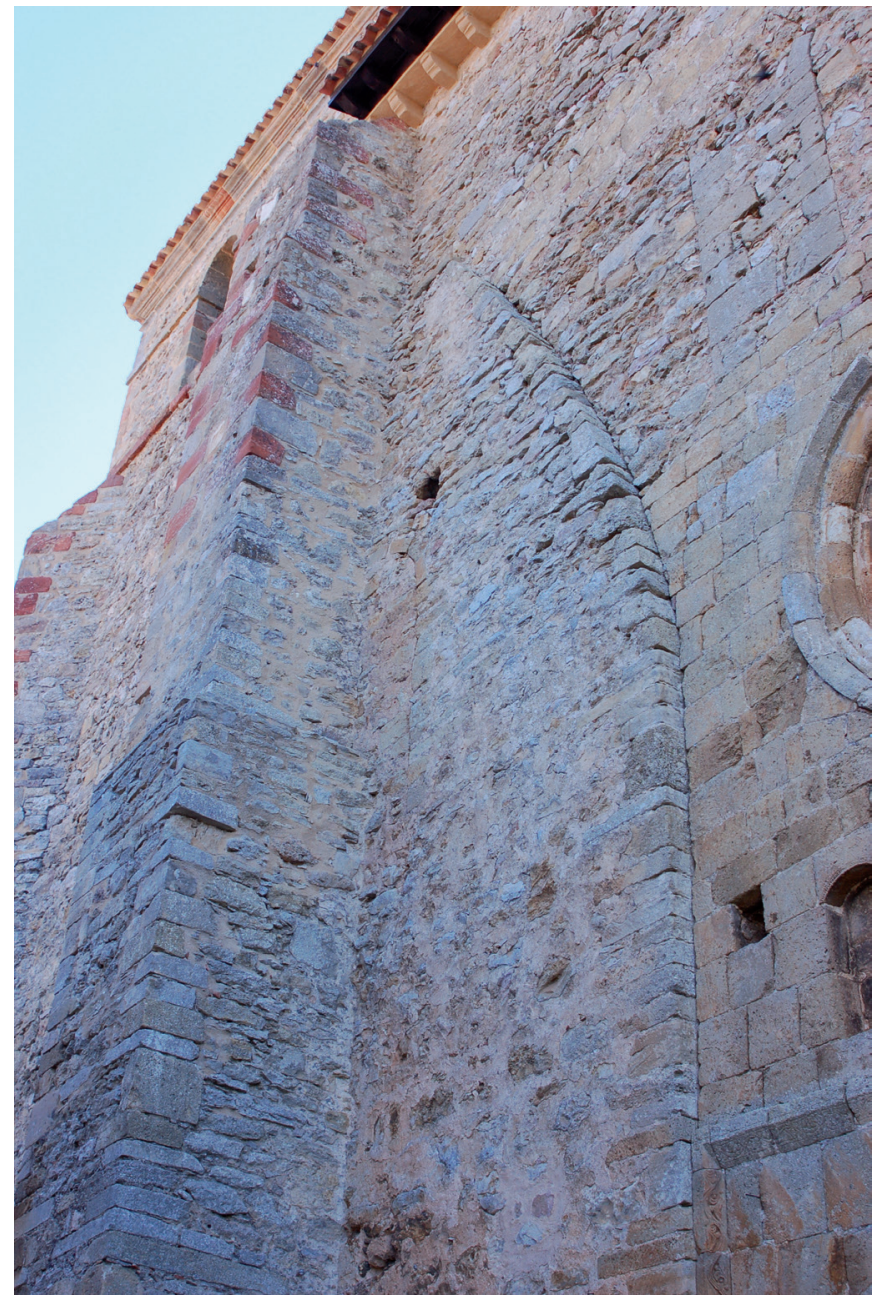

Fig. 15. Estructura con remate convexo en el hastial occidental de la iglesia. Etapa VII

Finalmente, recordar que la construcción del contrarresto meridional de la torre elimina evidencias de etapas anteriores. Por un lado, es desmantelada la fachada oeste de la nave septentrional de la iglesia románica, según se deduce de los restos conservados atribuibles a la etapa II y III, y por otro, a raíz de este desmantelamiento dejamos de conocer la verdadera dimensión del pórtico para cubrir la portada que se origina en la etapa IV.

La intervención del siglo XVII en el interior de la iglesia se hace menos evidente por la existencia de enfoscados y enlucidos. Los pilares laterales que dividen en dos tramos el occidente del aula (A118, UE1064) son de sección compuesta y se apean sobre sendas basas molduradas. Su remate superior se realiza mediante una moldura compuesta que también recorre los paños laterales de esta misma etapa. Dicha moldura se adosa en el lado sur a una imposta anterior, de época 
gótica, que habrá de ser cortada cuando se realiza esta obra. Sobre los apoyos que acabamos de describir se construyen dos bóvedas de cañón con lunetos que tipológicamente se corresponden con la etapa en la que nos encontramos.

Pero una obra de tal envergadura también hace necesaria una reorganización de los espacios. Así se realiza un nuevo coro (A118, UE1060 y 1062) en el tramo occidental del edificio con una arquería triple que sustenta un forjado de madera, al cual se accede a través de una escalera en codo situada en el ángulo noroccidental. Sus arcos apoyan sobre una pareja de columnas toscanas. Este coro pudo venir a sustituir a otro que ya debió existir, al menos, durante la Etapa VI.

Por último, en la capilla mayor se instala el retablo actual (A128, UE1092) de rasgos contemporáneos con esta etapa, con un camarín para la imagen de la Virgen en su composición, que es iluminado practicando la apertura de un vano en el testero oriental (A128, UE1055). La intervención se fecha en el año 1771 de acuerdo con la inscripción conservada en esta zona.

En resumen, esta etapa se identifica con las importantes reformas documentadas entre los siglos XVII y XVIII y con las que se concluyen los trabajos llevados a cabo en época gótica. Su realización debía de ser absolutamente necesaria para concluir dichos trabajos que, como vimos, acabaron de forma abrupta y que finalmente no pudieron llevarse a término hasta más de un siglo después. Esta será la última de las grandes obras realizadas en el templo.

\section{Etapa VIII. Ampliación de algunas estructuras en período neoclásico}

Las actuaciones de esta etapa poseen una doble naturaleza, centrándose en la funcionalidad y ornamentación de la iglesia. En lo que respecta a su ornamentación, algunas de las obras realizadas en la segunda mitad del siglo XVIII, poseen un aire verdaderamente clasicista que afianza esta cronología. En este sentido, hemos de mencionar la instalación del púlpito (A119, UE1073) en el primer pilar gótico del muro norte, con una figura desnuda de un atlante que sustenta el podio. También los elementos arquitectónicos recuperan este clasicismo. La introducción de la puerta en el muro sur (A119, UE1018), abierta hacia la sacristía, así lo constata, puesto que está compuesta por una pareja de pilastras jónicas que soportan un entablamento liso bajo frontón triangular (Fig. 16).

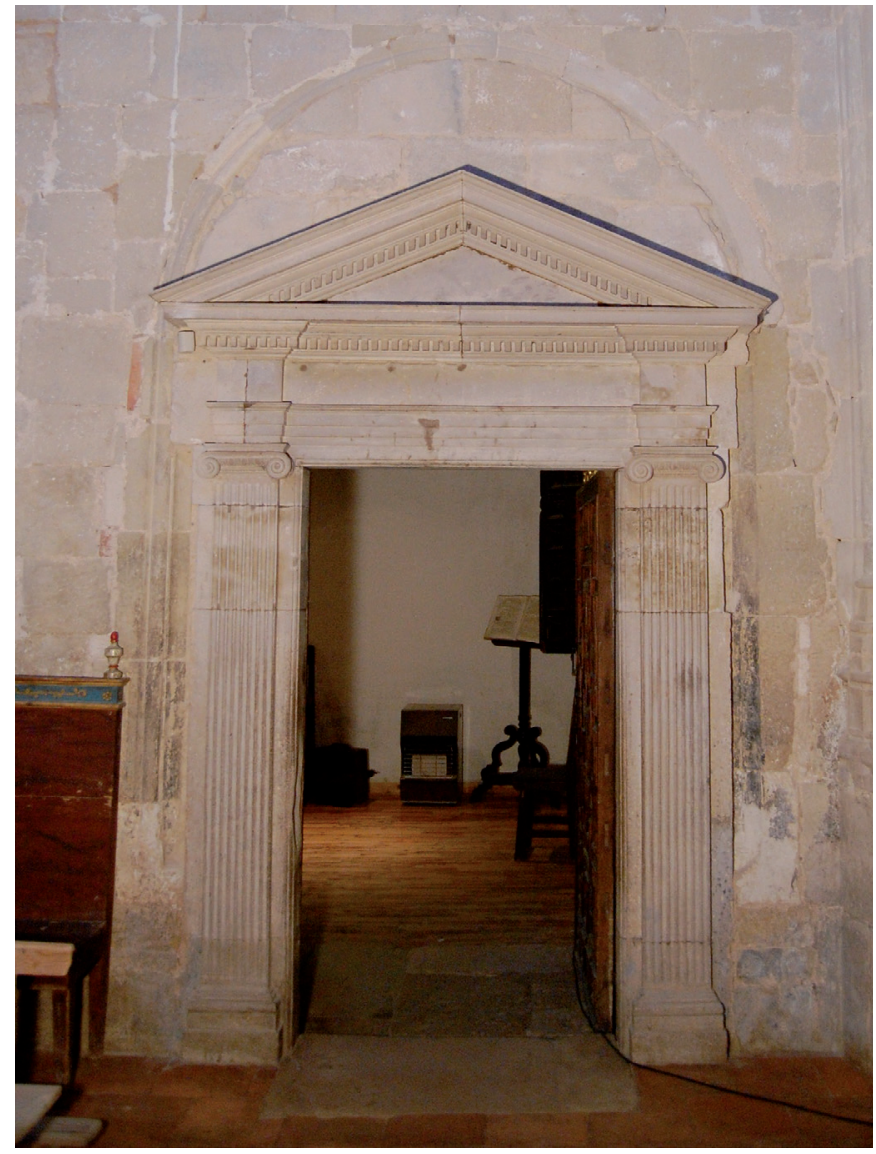

Fig. 16. Puerta de acceso a la sacristía desde el interior del aula

Es precisamente en el espacio de la sacristía donde podemos apreciar con ciertas garantías la magnitud de esta obra. En su interior, y en relación con la construcción de la puerta anteriormente mencionada, se eleva tanto el nivel del pavimento como el techo de la habitación de manera ostensible. Esta intervención queda reflejada en la construcción de un lienzo que combina mampostería y sillería reutilizada en el muro meridional de dicha estancia (A119, UE1046). Junto con este recrecido, se construye una ventana adintelada, mientras se ciegan las originarias de la estancia por quedar muy bajas con respecto al nuevo nivel de suelo.

Inmediatamente después de esta obra, tal vez dentro del mismo proyecto, se lleva a cabo el segundo piso de la claustra ${ }^{7}$ y su compartimentación interna. Una vez elevada la cota de uso y los muros de la sacristía, se construye el lienzo (A120, UE1047) que ocupa la mitad occidental de este espacio con mampuestos con

\footnotetext{
En la documentación sólo se habla de una claustra baja a partir del último cuarto del siglo XVIII (ADO-S, Libro 96/42, ff. 240v-241r. 1775, diciembre, $13)$.
} 


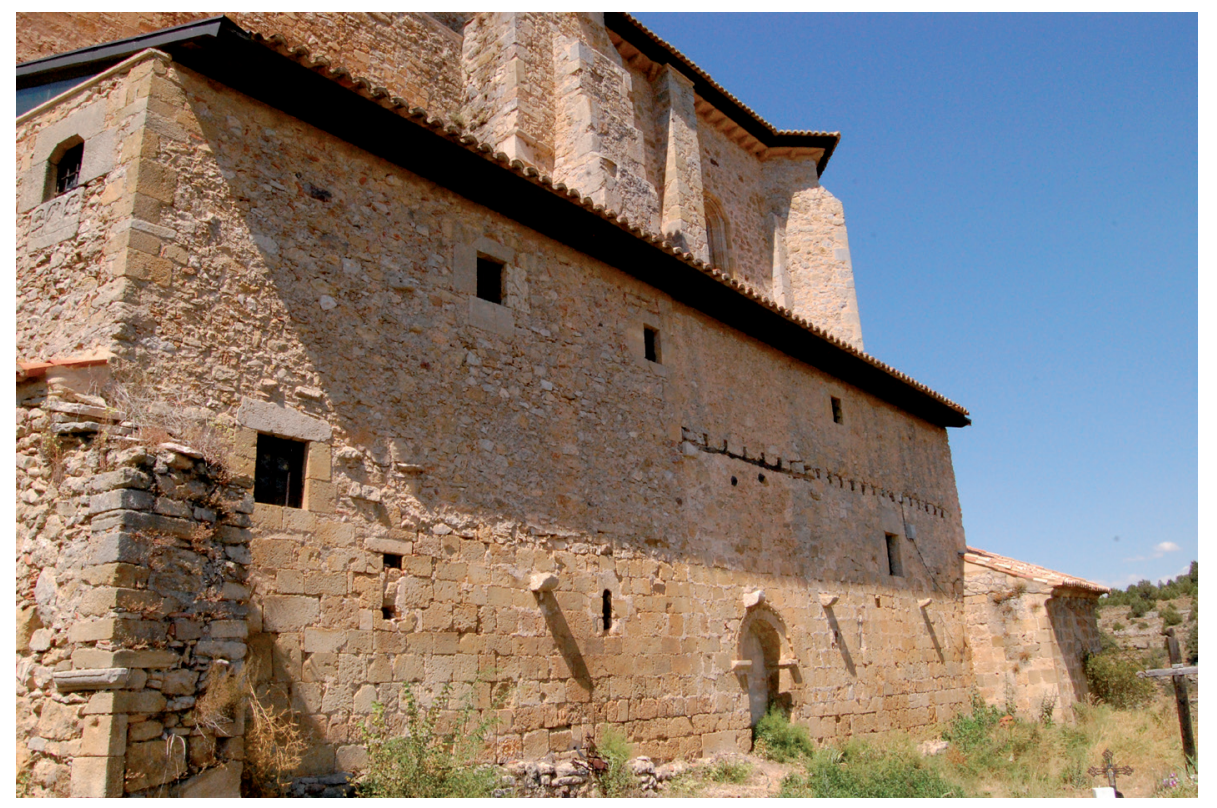

Fig. 17. Aspecto actual de la estancia sur de la iglesia con el segundo piso construido encadenados de sillares en las esquinas (Fig. 17). Pese a las evidentes fases constructivas, la tipología de sus elementos así como de las ventanas indica que el desarrollo oriental del muro pertenece a la misma obra, aunque la solución de continuidad existente nos ha llevado a individualizarlo en otra unidad (A120, UE1048). Igualmente, la factura de su fábrica apunta a que su cierre oeste (A120, UE1023 y 1044) se realiza durante la misma intervención. Destacamos aquí la reutilización de material medieval decorado, como el relieve con escenas de la Resurrección de Cristo que pudo pertenecer a un sarcófago (A120, A1024).

Del interior de este espacio solo podemos realizar conjeturas en base a la presencia de algunos agujeros y cortes en sus muros. Estos podrían ser los restos de las huellas de los travesaños que formaría parte un forjado de madera perteneciente a una cubierta (A120, UE1107 y 1108). El apoyo de esta estructura se realizaría en las ménsulas aquí existentes. En lo referente a la compartimentación de dicho espacio interior, el piso bajo posee dos tabiques (A120, UE1116 y 1119) que divide el total en tres y en el que el central sería el lugar por donde se ascendería al segundo piso. La segunda altura tal vez tuviera alguna división interna, como evidencia la existencia de varios agujeros (A120, UE1102 1103 y 1104).

\section{Etapa IX. Mantenimiento contemporáneo del templo. Siglos $X I X-X X$}

Lejos de todas las grandes reformas documentadas hasta ahora en los dos últimos siglos, las actuaciones contemporáneas se orientan hacia la conservación, mejora de las instalaciones y restauración, aunque responden a distintas formas de intervención.

Por lo que se refiere a las obras de conservación, la nave de la iglesia ha sido enfoscada en sus tramos central y occidental, resaltándose las ventanas y nervios de cubiertas con policromías (A122, UE1058). Las lagunas y humedades que le afectan denotan cierta antigüedad, sin que podamos precisar más en este sentido. Solamente contamos con la orientación que nos ofrece el grafito en el intradós de la ventana abierta en la fachada occidental (A118, UE1007), en el cual permanece escrita la fecha 1932. La ausencia de otras referencias y las características similares existentes entre ellos llevan a poner en relación estos enfoscados con otros aplicados en la capilla gótica (A122, UE 1115) o en el baptisterio (A122, UE1063).

Las mejoras en determinados aspectos de la iglesia se refieren a distintas actividades, como la inclusión de un reloj en la cara norte de la torre (A122, UE1026), el banco de piedra adosado en la parte inferior del hastial occidental (A122, UE1010) o el zócalo de mampuestos en la parte inferior del muro sur de la ampliación meridional (A122, UE1036), posiblemente construido como refuerzo ante la sustracción constante de terreno en este lado al tener un uso como cementerio. Al interior, se registran actuaciones como la de insertar un pequeño armario a los pies del templo (A122, UE1061), por el cual se llegó a romper parte del muro románico primitivo, o el corte de parte del muro correspondiente a la cabecera 
del primer templo gótico (Etapa III. A107, UE1051) para insertar un mueble de madera.

Finalmente, tenemos que enunciar las labores vinculadas a la última de las restauraciones llevadas a cabo (A120) ${ }^{8}$, entre las que se encuentran el alero de madera sobre el recrecido con modillones de piedra que remata todos los muros del edificio, las cubiertas de teja, los miradores de cristal en la segunda planta de la ampliación sur o la reposición de impostas y canecillos medievales.

Así pues, la heterogeneidad de las actuaciones llevadas a cabo en los últimos dos siglos responde a las necesidades del uso diario y al consecuente desgaste de la iglesia de Santa María, más que a la presencia de problemas que pongan en peligro la integridad del edificio.

\section{CONCLUSIÓN}

La realidad material de la iglesia de Nuestra Señora del Castillo nos ha dejado una rica secuencia arquitectónica conservada en sus muros (Fig. 18). Gracias a la conjunción de los datos procedentes de la estratigrafía muraria y de los testimonios documentales, la evolución constructiva del templo se vuelve mucho más rica desvelando una complejidad que hasta ahora no se conocía.

La primera novedad corresponde con la documentación de un edificio románico (Etapa I) del cual se conserva parte del hastial occidental y restos de los muros norte y sur. A pesar de la inconexión entre estos tres paños, sus características permiten defender la pertenencia a un mismo proyecto. Sin embargo no podemos definir cuál fue su planta, ni su función. Tampoco han quedado elementos ornamentales capaces de ofrecernos una mayor precisión cronológica, por lo que únicamente las referencias históricas al poblamiento medieval de la villa pueden situar su construcción en la primera mitad del siglo XII.

Esta primera edificación será objeto de modificaciones llevadas a cabo en esa misma centuria (Etapa II). Por un lado, se construye una nueva portada con material reutilizado en su fachada occidental, que no permite defender con rotundidad una función litúrgica para este edificio. Pero por otro, se edifica un nuevo cuerpo adosado al costado meridional del edificio originario, que por su organización interna, así como su posterior referencia en las fuentes modernas como claustra ${ }^{9}$, permite

\footnotetext{
8 Ver nota 1.

9 ADO-S, Libro 96/38, f. 6r. 1606, noviembre, 20.
}

suponer que este era un área de residencia para el clero encargado de los servicios y el cuidado del templo.

Posteriormente se lleva a cabo una nueva reforma en su fachada que permite definir la organización interna de la iglesia de Santa María (Etapa II/III), un aula de disposición tripartita con la nave central más elevada que las laterales, iluminada por un nuevo gran óculo abocinado. $\mathrm{Y}$ es este elemento el que sitúa cronológicamente su construcción en un momento más avanzado, de transición hacia fórmulas góticas.

Será difícil conseguir algo de información acerca de cuál fue la disposición de la fachada oriental de la iglesia, transformada desde este momento (Etapa III) para configurar un testero plano. La nueva construcción introduce en el templo un lenguaje diferente, definido en el estilo gótico. Y es en este momento también cuando se incluye una capilla lateral sobre su costado meridional.

La continuada utilización del templo requiere igualmente de pequeñas intervenciones que se concentran en la fachada principal (Etapa IV). La construcción de una espadaña en el piñón de la misma y la elevación de un pórtico que la cobija, son acciones que reflejan que la actividad no cesa incluso en fases que podemos llamar de transición por el hecho de no realizarse ninguna gran obra generalizada en la iglesia.

En el siglo XVI, coincidiendo con la pujanza económica de la familia de los Padilla en Calatañazor, se lleva a cabo la transformación más notable realizada en el templo (Etapa V). La búsqueda de un nuevo espacio interior, más alto, que permite incluir retablos de mayor dimensión, y las fórmulas constructivas del momento conllevan un proyecto que altera su fisonomía. Los altos muros y el sistema de cubiertas nervadas se contrarrestan con sólidos estribos que dotarán al templo de un aspecto abaluartado. Sin embargo, este gran proyecto no llegó a consumarse en su desarrollo a occidente y siendo tabicado con carácter temporal a la espera de alcanzar un momento apropiado para concluirlo. Así lo indica la identificación de un muro en el lado norte del edificio con la misma altura que los de la obra anterior, pero construido con material reutilizado. La apertura en este muro de un acceso a un posible coro a los pies, implica un cierto desarrollo temporal (Etapa VI).

Habrá que esperar hasta finales del siglo XVII para poder concluir de forma homogénea la reforma total del conjunto (Etapa VII). Es en este momento cuando se procede al cierre definitivo de los tramos central y occidental del templo así como a la elevación de la torre en la esquina noroccidental de la iglesia, quedando configurada 

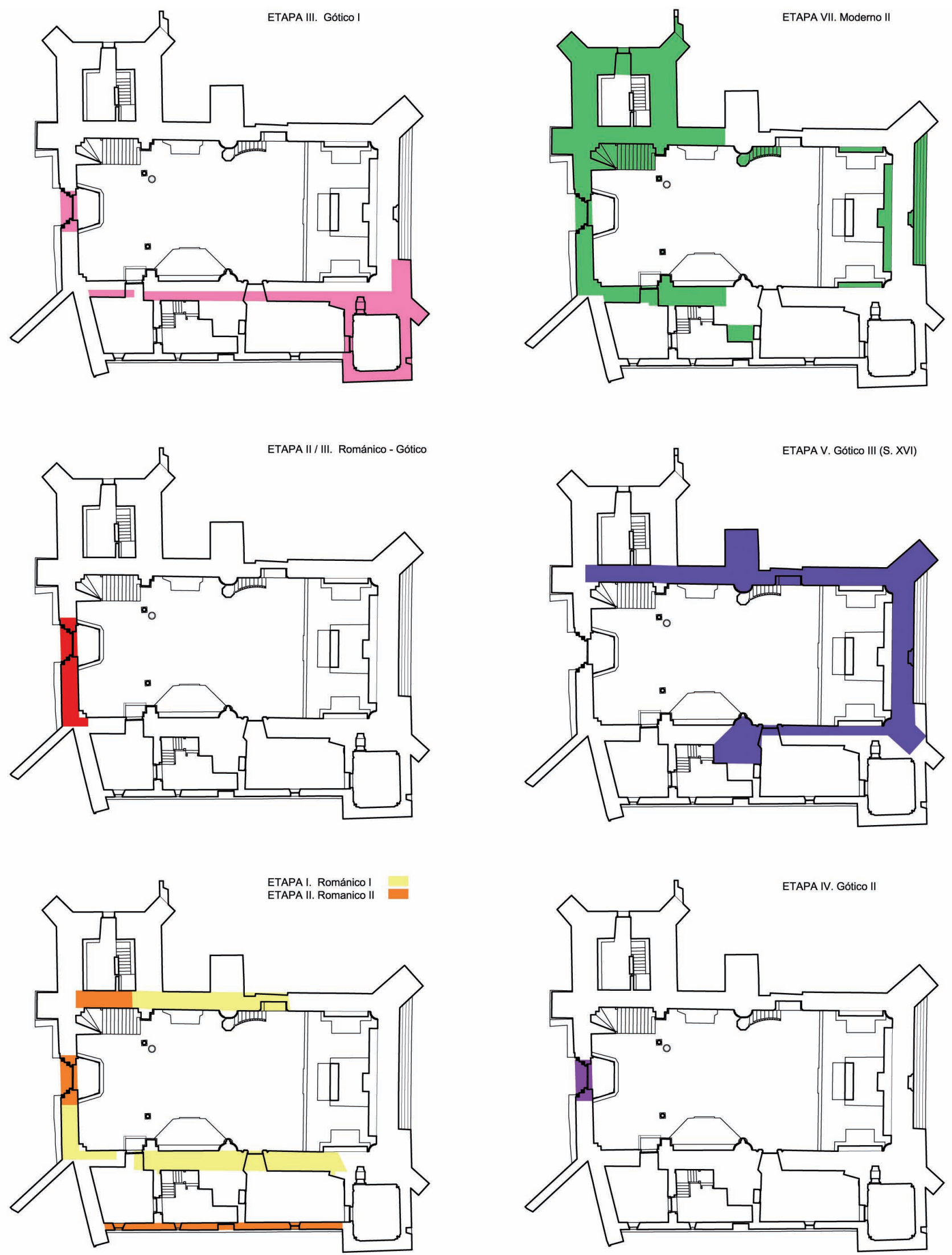

Fig. 18. Evolución de las fases constructivas del edificio a través de sus plantas 
su imagen actual. Los contrarrestos situados en los ángulos de dicho campanario se rematan con una morfología recta salvo el ubicado en el ángulo suroccidental, con un remate curvo. La construcción de este último, material y estratigráficamente coetáneo con el primer cuerpo de la torre, supuso la destrucción del tercio septentrional de la fachada oeste románica, desapareciendo así también los mechinales al norte donde estuvo anclada la cubierta del pórtico adosado a la portada de Occidente durante la Etapa IV.

La proyección de una segunda planta en el espacio agregado al costado sur se produce a lo largo de la "fase neoclásica" (Etapa VIII) debido a los elementos que adornan sus dos principales exponentes arquitectónicos: el púlpito y la portada de la sacristía, ambos construidos en 1790. La monumentalización de este espacio meridional, que incluye la elevación de su cota hasta ponerla al nivel actual, afectó a la reordenación del resto de los espacios inferiores del mismo.

Configurados sus rasgos básicos, los últimos doscientos años en la vida del edificio (Etapa IX) se han caracterizado por diversas actuaciones encaminadas a su mantenimiento, su mejora y su restauración. El revoco y enlucido de sus paramentos; la construcción de armarios en su interior y bancos exteriores; y la reparación de las cubiertas y reposición de sillares, dan cuenta del paso del tiempo en unos muros que siguen albergando las actuaciones asociadas al uso continuado de la iglesia de Nuestra Señora del Castillo.

\section{Referencias administrativas}

Este artículo resume el informe arqueológico resultante de la lectura de paramentos de la iglesia de Ntra. Sra. del Castillo (Moreno y Murillo, 2009. Iglesia de Nuestra Señora del Castillo. Calatañazor, Soria. Lectura de Paramentos. Informe manuscrito depositado en el Servicio Territorial de Cultura de la Junta de Castilla y León). El trabajo fue encargado por la Fundación Duques de Soria en el marco del Proyecto Cultural Soria Románica.
Asesor científico: Luis Caballero (Instituto de Historia, CSIC). Trabajo de campo: José Ignacio Murillo (arqueólogo, coordinador y tratamiento de la planimetría), Francisco J. Moreno (historiador del arte, redacción de la memoria, Dep. Historia del Arte I, UCM), María de los Ángeles Utrero (arqueóloga, IH, CSIC), Carlos Cauce (arqueólogo, IH, CSIC), Simona Trudu (historiadora del arte, Università di Cagliari), Maite Iris García (historiadora del arte, IH, CSIC), Rafael Martín (arquitecto, planimetría original, Escuela de Arquitectura, UPM) y Oskar Bell (arquitecto, planimetría original). Supervisión: Equipo Técnico del Proyecto Cultural Soria Románica. Fundación Duques de Soria. Recopilación de la documentación en archivo: Josemi Lorenzo (historiador, Proyecto Cultural Soria Románica).

La autoría de las figuras es de los autores del texto, salvo aquellas en las que se indica una referencia distinta.

\section{BIBLIOGRAFÍA}

García Gómez, F. 2012: Románico soriano. Arte y patrimonio, Valladolid. García Valenciano, J. J. 1982: Calatañazor donde el silencio es historia, El Burgo de Osma.

García Valenciano, J. J. 1986: Las tierras del suroeste soriano (Duero Joven, tierras llenas), Mancomunidad Turística de las Tierras del Suroeste de Soria, Almazán.

Gaya Nuño, J. A. 1946: El románico en la provincia de Soria, Madrid (Edición facsímil, 2003. Centro de Estudios Sorianos. Consejo Superior de Investigaciones Científicas).

Loperráez Corvalán, J. 1788: Descripción histórica del Obispado de Osma con tres disertaciones sobre los sitios de Numancia, Uxama y Clunia, 3 Tomos, Madrid. (Edición facsímil, 1978. Turner).

Martínez Frías, J. M. 1980: El gótico en Soria. Arquitectura y escultura monumental, Universidad de Salamanca y Diputación Provincial de Soria, Salamanca.

Martínez Hernando, M. C. 1984: "Los orígenes de la ciudad de Soria", Geographicalia 21-24, pp. 3-24.

Ruiz Ezquerro, J. J. 1990: "Las iglesias de Nafria y Calatañazor (Soria). Conjunción de influencias silenses e hispanomusulmanas", en El románico en Silos. IX Centenario de la consagración de la iglesia y el claustro, pp. 575-585.

Taracena, B. y Tudela, J. 1928: Guía artística de Soria y su provincia. Las Heras, Soria (Segunda edición, 1962. Revista de Occidente, Madrid). 


\section{Listado de Actividades}

\begin{tabular}{|c|c|c|c|c|c|c|}
\hline $\mathbf{P}$ & Act & Nombre Act & UE & Nombre UE & Ant a Act & Post a Act \\
\hline \multirow[t]{2}{*}{ I } & 101 & Muro occidental de sillería & 1001 & Fábrica sillería al Sur portada occidental. & $\begin{array}{ll}103 & 106 \\
120 & 122 \\
123 & 124\end{array}$ & \\
\hline & & & 1006 & $\begin{array}{l}\text { Pareja de mechinales en la sillería al Sur } \\
\text { portada occidental. }\end{array}$ & 101 & \\
\hline \multirow[t]{5}{*}{ I } & 102 & $\begin{array}{l}\text { Muros norte y sur aula } \\
\text { originaria }\end{array}$ & 1028 & $\begin{array}{l}\text { Fábrica de sillería muro Norte aula, parte } \\
\text { inferior. }\end{array}$ & $\begin{array}{l}102112 \\
114117119 \\
123129 \\
130\end{array}$ & \\
\hline & & & 1031 & Mechinales en fábrica de la UE1028. & & 102 \\
\hline & & & 1082 & $\begin{array}{l}\text { Muro sillería cuerpo inferior primer y } \\
\text { segundo tramos. }\end{array}$ & $\begin{array}{l}106107 \\
112119120 \\
122128 \\
131134\end{array}$ & \\
\hline & & & 1097 & $\begin{array}{l}\text { Muro sillería con esquina alzado } \\
\text { meridional. }\end{array}$ & $\begin{array}{l}107109 \\
112120 \\
122123 \\
134\end{array}$ & \\
\hline & & & 1122 & $\begin{array}{l}\text { Muro de sillería con esquina muro Sur } \\
\text { torre. }\end{array}$ & 104117 & \\
\hline II & 103 & $\begin{array}{l}\text { Portada occidental } \\
\text { remontada }\end{array}$ & 1002 & $\begin{array}{l}\text { Portada occidental, su lienzo superior que } \\
\text { incluye arcos ciegos. }\end{array}$ & $\begin{array}{l}106117 \\
122125\end{array}$ & 101 \\
\hline II & 104 & $\begin{array}{l}\text { Extremo occidental del } \\
\text { muro norte }\end{array}$ & 1121 & $\begin{array}{l}\text { Muro de sillería adosado esquina Oeste } \\
\text { muro UE1122. }\end{array}$ & 114117 & 102 \\
\hline II & 105 & Ampliación cuerpo sur & 1037 & $\begin{array}{l}\text { Fábrica de sillería reutilizada en muro } \\
\text { Sur. }\end{array}$ & $\begin{array}{l}108109 \\
119120 \\
122127\end{array}$ & \\
\hline \multirow[t]{2}{*}{ II } & 127 & $\begin{array}{l}\text { Reforma en ampliación sur } \\
\text { exterior }\end{array}$ & 1038 & $\begin{array}{l}\text { Ménsulas para durmiente madera muro } \\
\text { Sur. }\end{array}$ & & 105 \\
\hline & & & 1040 & $\begin{array}{l}\text { Ampliación de la luz del vano de medio } \\
\text { punto en muro Sur. }\end{array}$ & & 105 \\
\hline \multirow[t]{3}{*}{ II/III } & 106 & $\begin{array}{l}\text { Remate hastial occidental. } \\
\text { Óculo }\end{array}$ & 1003 & $\begin{array}{l}\text { Fábrica sillería y óculo parte intermedia } \\
\text { fachada Oeste. }\end{array}$ & $\begin{array}{ll}110 & 111117 \\
118 & 120 \\
124 & 125\end{array}$ & 101103 \\
\hline & & & 1004 & $\begin{array}{l}\text { Sillar retallado en su cara externa con } \\
\text { motivo circular. }\end{array}$ & & 101 \\
\hline & & & 1086 & Sillar con retalle circular en su cara vista. & & 102 \\
\hline \multirow[t]{3}{*}{ III } & 107 & Ampliación cabecera & 1035 & $\begin{array}{l}\text { Hilada de sillares en parte baja de la } \\
\text { esquina Este del muro Norte. }\end{array}$ & 112 & \\
\hline & & & 1051 & $\begin{array}{l}\text { Fábrica de sillería con arco ojival en } \\
\text { ángulo Sureste de la iglesia. }\end{array}$ & 112123 & 107 \\
\hline & & & 1098 & $\begin{array}{l}\text { Lienzo de sillares escantillados y con } \\
\text { gruesas juntas en muro Sur. }\end{array}$ & 123 & 102112134 \\
\hline
\end{tabular}




\begin{tabular}{|c|c|c|c|c|c|c|}
\hline $\mathbf{P}$ & Act & Nombre Act & $\mathbf{U E}$ & Nombre UE & Ant a Act & Post a Act \\
\hline & & & 1101 & $\begin{array}{l}\text { Fábrica de sillería con remate de cornisa } \\
\text { sobre canecillos lisos. Muro Sur. }\end{array}$ & $\begin{array}{ll}107 & 120 \\
128 & 134\end{array}$ & 102 \\
\hline III & 108 & Capilla meridional & 1049 & $\begin{array}{l}\text { Capilla anexa en el ángulo Suroeste de la } \\
\text { iglesia. }\end{array}$ & $\begin{array}{ll}119 & 121 \\
122 & 123 \\
132 & \end{array}$ & 105107 \\
\hline \multirow[t]{3}{*}{ III } & 109 & $\begin{array}{l}\text { Extremo occidental del } \\
\text { muro sur. Baptisterio }\end{array}$ & 1039 & $\begin{array}{l}\text { Apertura de vano adintelado en extremo } \\
\text { Oeste de muro Sur en parte baja. }\end{array}$ & & 105 \\
\hline & & & 1091 & $\begin{array}{l}\text { Puerta de medio punto en muro Sur, } \\
\text { tercer tramo bajo coro. }\end{array}$ & 117 & 102 \\
\hline & & & 1095 & $\begin{array}{l}\text { Fábrica de mampuesto rematada en } \\
\text { canecillos de nacela. }\end{array}$ & 123 & \\
\hline III & 110 & $\begin{array}{l}\text { Pequeño vano sobre óculo } \\
\text { hastial occidental }\end{array}$ & 1011 & Apertura de vano sobre óculo a eje. & 111 & 106 \\
\hline \multirow[t]{3}{*}{ III } & 130 & $\begin{array}{l}\text { Posible coro en segundo } \\
\text { tramo norte }\end{array}$ & 1066 & $\begin{array}{l}\text { Rotura vertical en muro Norte interior. } \\
\text { Segundo tramo. }\end{array}$ & 130 & 102 \\
\hline & & & 1067 & Agujeros cuadrados en muro Norte. & & 102 \\
\hline & & & 1068 & Agujero. Posible tornapunta. & & 102 \\
\hline IV & 111 & Espadaña hastial occidental & 1013 & $\begin{array}{l}\text { Espadaña de piedra sobre el piñón de la } \\
\text { primitiva fachada. }\end{array}$ & 117 & 110 \\
\hline \multirow[t]{4}{*}{ IV } & 124 & $\begin{array}{l}\text { Adosamiento estructura en } \\
\text { esquina suroeste }\end{array}$ & 1005 & $\begin{array}{l}\text { Agujero parte baja esquina Sur fachada } \\
\text { occidental. }\end{array}$ & & 101 \\
\hline & & & 1009 & $\begin{array}{l}\text { Tres agujeros en mitad Sur fachada } \\
\text { occidental. }\end{array}$ & 117 & 106 \\
\hline & & & 1096 & Roza diagonal cortando la UE1095 & & 109 \\
\hline & & & 1117 & Rotura de ángulo Sur fachada occidental. & & 106 \\
\hline IV & 125 & $\begin{array}{l}\text { Posible pórtico en fachada } \\
\text { occidental }\end{array}$ & 1008 & $\begin{array}{l}\text { Tres mechinales sobre portada de } \\
\text { Occidente. }\end{array}$ & & 103106 \\
\hline IV & 136 & $\begin{array}{l}\text { Agujeros en la pared del } \\
\text { baptisterio }\end{array}$ & 1128 & $\begin{array}{l}\text { Agujeros en pared norte baptisterio } \\
\text { reparados }\end{array}$ & & 109 \\
\hline \multirow[t]{6}{*}{ V } & 112 & $\begin{array}{l}\text { Ampliación abovedada } \\
\text { tramo oriental aula }\end{array}$ & 1029 & $\begin{array}{l}\text { Fábrica de sillería en parte alta de muro } \\
\text { Norte y contrafuertes. }\end{array}$ & 117123 & $\begin{array}{lll}102 & 107 & 113 \\
114 & 118 & 119 \\
122 & 123 & 126 \\
128 & 129 & \end{array}$ \\
\hline & & & 1032 & $\begin{array}{l}\text { Corte de sillares en jamba Oeste de la } \\
\text { puerta Norte. }\end{array}$ & & 102 \\
\hline & & & 1033 & $\begin{array}{l}\text { Cegado de puerta Norte y corte de su } \\
\text { umbral. }\end{array}$ & & 102 \\
\hline & & & 1034 & $\begin{array}{l}\text { Corte y cegado de vano a occidente de } \\
\text { portada Norte. }\end{array}$ & 117123 & 102 \\
\hline & & & 1052 & $\begin{array}{l}\text { Fábrica de mampostería parte alta muro } \\
\text { Sur y Este y contrafuertes. }\end{array}$ & $\begin{array}{l}117119 \\
123128\end{array}$ & 102107112 \\
\hline & & & 1054 & $\begin{array}{l}\text { Contrafuerte de mampostería y sillería en } \\
\text { esquina SE. }\end{array}$ & 112 & 107 \\
\hline
\end{tabular}




\begin{tabular}{|c|c|c|c|c|c|c|}
\hline $\mathbf{P}$ & Act & Nombre Act & UE & Nombre UE & Ant a Act & Post a Act \\
\hline & & & 1056 & Corte muro UE1051 en alzado oriental. & 112 & 107 \\
\hline & & & 1069 & Cruz incisa en muro Norte interior. & & 102 \\
\hline & & & 1071 & $\begin{array}{l}\text { Cegado de puerta junto a pilar gótico en } \\
\text { muro Norte segundo tramo. }\end{array}$ & 130 & 102 \\
\hline & & & 1072 & $\begin{array}{l}\text { Pilares compuestos facetados, cubierta de } \\
\text { terceletes e imposta. }\end{array}$ & 122 & 102 \\
\hline & & & 1074 & $\begin{array}{l}\text { Apertura de puerta gótica en primer } \\
\text { tramo de muro Norte. }\end{array}$ & & 102 \\
\hline & & & 1087 & $\begin{array}{l}\text { Apertura de puerta gótica primer tramo } \\
\text { de muro Sur. }\end{array}$ & 119 & 102 \\
\hline & & & 1089 & $\begin{array}{l}\text { Apertura vertical junto a puerta } \\
\text { neoclásica }\end{array}$ & 122 & 102 \\
\hline $\mathrm{V}$ & 113 & Pinturas testero cabecera & 1093 & Pinturas de la testera. & 128 & 112 \\
\hline V & 114 & $\begin{array}{l}\text { Cierre temporal en muro } \\
\text { norte aula }\end{array}$ & 1030 & $\begin{array}{l}\text { Fábrica de mampuestos y sillares } \\
\text { reutilizados en muro Norte junto a } \\
\text { esquina N-E de torre. }\end{array}$ & 117123 & 102104112 \\
\hline VI & 115 & $\begin{array}{l}\text { Puerta extremo occidental } \\
\text { muro norte aula }\end{array}$ & 1123 & $\begin{array}{l}\text { Apertura de puerta en muro de la } \\
\text { UE1030. }\end{array}$ & 117133 & 114 \\
\hline VI & 116 & $\begin{array}{l}\text { Grieta cuerpo medio } \\
\text { extremo occidental muro } \\
\text { norte aula }\end{array}$ & 1125 & Grieta muro Sur interior torre. & & 114 \\
\hline \multirow[t]{8}{*}{ VII } & 117 & $\begin{array}{l}\text { Elevación testero occidental } \\
\text { y meridional, construcción } \\
\text { cuerpo torre }\end{array}$ & 1012 & Relleno de mampostería en diagonal. & 117 & 106124 \\
\hline & & & 1014 & $\begin{array}{l}\text { Introducción de paño de mampostería al } \\
\text { Norte fachada Oeste. }\end{array}$ & 117122 & 103106 \\
\hline & & & 1017 & Escultura reutilizada en el hastial. & & \\
\hline & & & 1018 & $\begin{array}{l}\text { Fábrica mampuesto y sillería parte alta } \\
\text { tramos occidentales. }\end{array}$ & $\begin{array}{l}117118 \\
123\end{array}$ & $\begin{array}{l}106109110 \\
111112114 \\
117\end{array}$ \\
\hline & & & 1021 & $\begin{array}{l}\text { Torre de mampostería en ángulo } \\
\text { nororiental }\end{array}$ & $\begin{array}{l}117118 \\
122126\end{array}$ & 102114 \\
\hline & & & 1053 & $\begin{array}{l}\text { Contrafuerte de mampuesto y sillería en } \\
\text { el centro del muro Sur. }\end{array}$ & 123 & 112 \\
\hline & & & 1064 & $\begin{array}{l}\text { Pilares triples entre segundo y tercer } \\
\text { tramo aula. }\end{array}$ & & \\
\hline & & & 1127 & Puerta adovelada acceso baptisterio & & \\
\hline \multirow[t]{3}{*}{ VII } & 118 & $\begin{array}{l}\text { Cuerpo campanas torre } \\
\text { y cubiertas de los tramos } \\
\text { occidentales }\end{array}$ & 1007 & $\begin{array}{l}\text { Ventana adintelada abierta fachada } \\
\text { occidental. }\end{array}$ & & 106 \\
\hline & & & 1019 & Grietas (3) en la UE1018. & & 111117 \\
\hline & & & 1022 & $\begin{array}{l}\text { Cuerpo de campanas y elevación de } \\
\text { contrafuerte. }\end{array}$ & & 117118 \\
\hline
\end{tabular}




\begin{tabular}{|c|c|c|c|c|c|c|}
\hline $\mathbf{P}$ & Act & Nombre Act & $\mathbf{U E}$ & Nombre UE & Ant a Act & Post a Act \\
\hline & & & 1022 & Recrecido cuerpo superior torre. & & 117118 \\
\hline & & & 1059 & Puerta occidental de madera. & 122 & 103 \\
\hline & & & 1060 & Coro a los pies. & 122 & 117118 \\
\hline & & & 1062 & Escalera de subida al coro alto. & 118122 & 117 \\
\hline & & & 1079 & $\begin{array}{l}\text { Armario abierto en muro Sur, a la altura } \\
\text { del coro. }\end{array}$ & 122 & 109 \\
\hline & & & 1081 & $\begin{array}{l}\text { Rotura de imposta gótica en muro Sur, } \\
\text { segundo tramo. }\end{array}$ & & 112 \\
\hline VII & 119 & $\begin{array}{l}\text { Conexión entre aula y } \\
\text { cuerpo sur a través de } \\
\text { puerta neoclásica }\end{array}$ & 1090 & $\begin{array}{l}\text { Retablo adosado en muro Sur junto a } \\
\text { esquina S-E. }\end{array}$ & & 102112 \\
\hline VII & 126 & Cementerio norte & 1025 & $\begin{array}{l}\text { Puerta de acceso al cementerio Norte y } \\
\text { cerca. }\end{array}$ & & 112117 \\
\hline \multirow[t]{5}{*}{ VII } & 128 & $\begin{array}{l}\text { Apertura ventana en } \\
\text { cabecera y retablo mayor }\end{array}$ & 1055 & $\begin{array}{l}\text { Apertura de ventana en el centro de la } \\
\text { cabecera (año 1771) y refuerzo inferior. }\end{array}$ & & 107112 \\
\hline & & & 1083 & $\begin{array}{l}\text { Apertura de vano con arco de medio } \\
\text { punto rebajado en la UE1082, también al } \\
\text { exterior. }\end{array}$ & & 102107123 \\
\hline & & & 1084 & $\begin{array}{l}\text { Pareja de agujeros en la misma hilada de } \\
\text { la UE1082. }\end{array}$ & 122 & 102 \\
\hline & & & 1085 & $\begin{array}{l}\text { Dos agujeros sellados con taco de piedra } \\
\text { en la UE1082. }\end{array}$ & & 102 \\
\hline & & & 1092 & Retablo mayor de la cabecera. & & 112113 \\
\hline \multirow[t]{4}{*}{ VII } & 129 & Retablos modernos & 1065 & $\begin{array}{l}\text { Banco para altar en el segundo tramo } \\
\text { muro Norte. }\end{array}$ & & 102 \\
\hline & & & 1070 & $\begin{array}{l}\text { Agujero cegado junto a esquina del pilar } \\
\text { occidental en muro Norte. }\end{array}$ & & 102 \\
\hline & & & 1075 & Retablo adosado en muro Norte. & & 112 \\
\hline & & & 1080 & $\begin{array}{l}\text { Retablo barroco con crucificado gótico } \\
\text { adosado al muro Sur. }\end{array}$ & & 102 \\
\hline VII & 133 & Cegado puerta UE 1123 & 1124 & Cerramiento de vano de la UE1123. & 117 & 115 \\
\hline VII & 134 & Retirada cubierta claustra & 1120 & Corte de cubierta fachada Sur. & 107123 & $\begin{array}{l}102107112 \\
117128\end{array}$ \\
\hline \multirow[t]{4}{*}{ VIII } & 119 & $\begin{array}{l}\text { Conexión entre aula y } \\
\text { cuerpo sur a través de } \\
\text { puerta neoclásica }\end{array}$ & 1041 & $\begin{array}{l}\text { Cegado de vano con cenefa portada en } \\
\text { muro Sur. }\end{array}$ & & 105 \\
\hline & & & 1042 & $\begin{array}{l}\text { Cegado de vano de medio punto extremo } \\
\text { Este muro Sur. }\end{array}$ & & 105 \\
\hline & & & 1046 & $\begin{array}{l}\text { Fábrica de mampuesto y sillería } \\
\text { reutilizada parte intermedia muro Sur y } \\
\text { cegado huecos de forjado. }\end{array}$ & 120123 & 105 \\
\hline & & & 1073 & Púlpito. & & 102112 \\
\hline
\end{tabular}




\begin{tabular}{|c|c|c|c|c|c|c|}
\hline $\mathbf{P}$ & Act & Nombre Act & $\mathbf{U E}$ & Nombre UE & Ant a Act & Post a Act \\
\hline & & & 1088 & $\begin{array}{l}\text { Apertura puerta neoclásica en primer } \\
\text { tramo muro Sur. }\end{array}$ & 120122 & 102112 \\
\hline & & & 1113 & $\begin{array}{l}\text { Introducción de puerta de acceso capilla } \\
\text { gótica y corte arco bóveda. }\end{array}$ & 122 & 108 \\
\hline \multirow[t]{16}{*}{ VIII } & 120 & $\begin{array}{l}\text { Elevación segundo } \\
\text { piso cuerpo sur y } \\
\text { compartimentación interna } \\
\text { planta baja }\end{array}$ & 1023 & $\begin{array}{l}\text { Muro Oeste de la ampliación Sur, parte } \\
\text { superior. }\end{array}$ & 123 & 101 \\
\hline & & & 1024 & Pieza decorada reutilizada en la UE1023. & & \\
\hline & & & 1043 & Cegado de portada en muro Sur. & & 105 \\
\hline & & & 1044 & $\begin{array}{l}\text { Muro Oeste de ampliación Sur, parte } \\
\text { baja. }\end{array}$ & 122123 & 101105 \\
\hline & & & 1047 & $\begin{array}{l}\text { Fábrica de mampuesto y esquinas de } \\
\text { sillería en mitad Oeste muro Sur. }\end{array}$ & 120123 & 105119 \\
\hline & & & 1048 & $\begin{array}{l}\text { Fábrica de mampuesto cuerpo superior } \\
\text { ampliación Sur. }\end{array}$ & 123 & 119120 \\
\hline & & & 1102 & $\begin{array}{l}\text { Grupo de agujeros irregulares sobre vano } \\
\text { adintelado de UE1101. }\end{array}$ & & 107 \\
\hline & & & 1103 & $\begin{array}{l}\text { Agujero rectangular cortando UE1101 y } \\
\text { posterior relleno. }\end{array}$ & & 107 \\
\hline & & & 1104 & Agujero cegado cortando la UE1051. & & 107 \\
\hline & & & 1106 & $\begin{array}{l}\text { Agujero en enjuta Este puerta Sur } \\
\text { cegada, al interior. }\end{array}$ & & 105 \\
\hline & & & 1107 & $\begin{array}{l}\text { Cuatro agujeros cortando las UEs } 1046 \\
1053 \text { y } 1119 .\end{array}$ & & 117119120 \\
\hline & & & 1108 & Pareja de agujeros en la UE1046 & & 119120 \\
\hline & & & 1110 & $\begin{array}{l}\text { Introducción de ménsulas para durmiente } \\
\text { de madera en sacristía. }\end{array}$ & & 102119 \\
\hline & & & 1111 & $\begin{array}{l}\text { Corte de muro de la UE1082 para } \\
\text { introducir mascarón. }\end{array}$ & 122 & 102 \\
\hline & & & 1116 & $\begin{array}{l}\text { Muro con puerta que separa baptisterio y } \\
\text { escalera en ampliación Sur. }\end{array}$ & 122 & 102105120 \\
\hline & & & 1119 & $\begin{array}{l}\text { Muro perpendicular interior adosado a la } \\
\text { ampliación Sur. }\end{array}$ & 122 & 105112117 \\
\hline VIII & 121 & Instalación caja fuerte & 1114 & $\begin{array}{l}\text { Modificación de bóveda en capilla y } \\
\text { construcción cámara de seguridad. }\end{array}$ & 122 & 107108112 \\
\hline VIII & 132 & $\begin{array}{l}\text { Grieta en cara este capilla } \\
\text { sur }\end{array}$ & 1118 & Grieta en la fachada Este de la UE1118. & & 108 \\
\hline VIII & 135 & Puerta baptisterio & 1126 & Apertura puerta baptisterio & & 102109 \\
\hline \multirow[t]{2}{*}{ IX } & 122 & $\begin{array}{l}\text { Ampliación abovedada } \\
\text { tramo oriental aula }\end{array}$ & 1016 & Agujero parte superior de la UE1014. & & 117 \\
\hline & & & 1010 & $\begin{array}{l}\text { Banco de piedra adosado en parte baja } \\
\text { fachada Oeste. }\end{array}$ & & 101103117 \\
\hline
\end{tabular}




\begin{tabular}{|c|c|c|c|c|c|c|}
\hline $\mathbf{P}$ & Act & Nombre Act & $\mathbf{U E}$ & Nombre UE & Ant a Act & Post a Act \\
\hline & & & 1015 & Agujero en parte baja de la UE1014. & & 117 \\
\hline & & & 1026 & Reloj en la cara Norte de la torre. & & 117 \\
\hline & & & 1036 & $\begin{array}{l}\text { Zócalo de mampuestos en parte baja } \\
\text { muro Sur. }\end{array}$ & & 105120 \\
\hline & & & 1045 & $\begin{array}{l}\text { Corte de la UE1044 en su extremo Sur. } \\
\text { Posible puerta. }\end{array}$ & 123 & 120 \\
\hline & & & 1050 & $\begin{array}{l}\text { Cegado de la rotura en el muro Sur de la } \\
\text { UE1049 }\end{array}$ & & 108 \\
\hline & & & 1058 & $\begin{array}{l}\text { Enlucido, escayola y pintura de tramo } \\
\text { occidental interior. }\end{array}$ & & $\begin{array}{l}102103106 \\
112117118 \\
122\end{array}$ \\
\hline & & & 1061 & $\begin{array}{l}\text { Agujero con puerta de madera abierto en } \\
\text { el muro de la fachada interior occidental. }\end{array}$ & 122 & 101 \\
\hline & & & 1063 & Enlucido con zócalo del baptisterio. & & \\
\hline & & & 1076 & $\begin{array}{l}\text { Línea de agujeros sobre imposta gótica } \\
\text { cegados con ladrillo y enlucido de cal } \\
\text { muro Norte y Sur. }\end{array}$ & & 112 \\
\hline & & & 1077 & $\begin{array}{l}\text { Pareja de agujeros sobre ventanas del } \\
\text { muro Norte y Sur. }\end{array}$ & & 112 \\
\hline & & & 1078 & $\begin{array}{l}\text { Pérdida de nervaduras góticas y pinjantes } \\
\text { de las claves. }\end{array}$ & & 112 \\
\hline & & & 1105 & $\begin{array}{l}\text { Escalera de madera y forjado de la } \\
\text { ampliación Sur. }\end{array}$ & & $\begin{array}{ll}102 & 107109 \\
112 & 117119 \\
120\end{array}$ \\
\hline & & & 1109 & Corte de contrafuerte. & & 102107 \\
\hline & & & 1115 & Encalado sacristía y capilla gótica. & & 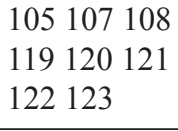 \\
\hline \multirow[t]{6}{*}{ IX } & 123 & $\begin{array}{l}\text { Restauración } \\
\text { contemporánea }\end{array}$ & 1020 & $\begin{array}{l}\text { Alero moderno de restauración ( igual } \\
\text { restauración contemporánea). }\end{array}$ & & $\begin{array}{l}107108112 \\
117118119 \\
120130\end{array}$ \\
\hline & & & 1027 & $\begin{array}{l}\text { Reposición de sillares. Restauración } \\
\text { contemporánea en el muro Norte. }\end{array}$ & & 102112114 \\
\hline & & & 1057 & Huella vertical desmonte muro. & & 107120 \\
\hline & & & 1094 & $\begin{array}{l}\text { Fábrica de mampostería y sillares } \\
\text { reutilizados en muro Sur. }\end{array}$ & 123 & 101102 \\
\hline & & & 1099 & $\begin{array}{l}\text { Roza sellada con mampuestos cortando } \\
\text { UE1097 y } 1098 \text { (relleno). }\end{array}$ & & 134 \\
\hline & & & 1100 & $\begin{array}{l}\text { Hilada de sillares repuestos cortando la } \\
\text { UE1082. Posible huella de cubierta. }\end{array}$ & & 134 \\
\hline IX & 131 & $\begin{array}{l}\text { Corte vertical en muro UE } \\
1082\end{array}$ & 1112 & $\begin{array}{l}\text { Corte vertical en la UE1082. Posible } \\
\text { tornapunta. }\end{array}$ & & 102 \\
\hline
\end{tabular}




\section{Apéndice Documental ${ }^{10}$}

(Lectura y transcripción de Josemi Lorenzo Arribas. Proyecto Cultural Soria Románica)

1606, noviembre, 20 (ADO-S, Libro 96/38, f. 6r-v): Se le cargan 40 reales en que se remató cierta madera de enebro que son vigas, pies y ciertos cabrios, todo de enebro, y se apregonó públicamente y es de lo que se deshizo de la claustra. || (f. 6v) 108 ducados de retejar la iglesia y capilla de San Pedro, y 22 reales por desechar en la claustra y echar dos cabrios nuevos en la capilla de San Pedro, que pagó a Rodrigo de Esteban, carpintero, vecino de Herreros, de que dio carta de pago.

1630, diciembre, 16 (ADO-S, Libro 96/38, f. 162v): Mando que se abra un poco más, conforme el cuadro tiene, la ventana que está en la sacristía, poniéndole una reja de hierro para que esté segura, atento hay poca claridad en ella, lo cual se haga luego.

1645, junio, 8 (ADO-S, Libro 96/40, 4r): Dio por descargo y se le recibe en cuenta 7.594 reales que pareció haber pagado a Pedro Navarro, maestro de cantería, que está haciendo la obra de la dicha iglesia, con licencia de su señoría, hasta $1^{\circ}$ de junio de [16]45, como consta por cartas de pago firmadas de su nombre.

1647, julio, 17 (ADO-S, Libro 96/40, 11r): [al margen: Bóvedas y columnas, o pilastras] Primeramente dio por descargo dicho Marcos de Vinuesa y se le reciben en cuenta 4.936 reales que parece haber pagado a Pedro Navarro, maestro de la obra, que hizo en la dicha iglesia, en que entran 2.000 reales que su señoría ilustrísima mandó darle para las dos columnas y los 1.000 reales que, además del concierto principal de la obra, le mandó dar su señoría cuando la vino a ver en 3 de octubre de 1646, como constó por cartas de pago firmadas de su nombre con que se le ha hecho de pagar la obra que hizo en dicha iglesia. || Dio por descargo y se le reciben en cuenta 600 reales que pagó a dicho Pedro Navarro de hacer el cancel que está a la puerta de la iglesia y abrir la ventana para dar luz al altar mayor, que fue concertado por su señoría ilustrísima en la villa del Burgo de Osma en 13 de enero de este año de 1647, de que dio carta de pago.

\footnotetext{
10 La serie de libros de fábrica consultada en el ADO-S comprende: Libro 96/38: Libro $1^{\circ}$ de Carta Cuenta e inventario (1606-1701); Libro 96/39: Libro de Carta Cuenta e Inventario (1795-1878); Libro 96/40: Libro de Carta Cuenta e Inventario (1645-1710); Libro 96-41: Libro $3^{\circ}$ de Carta Cuenta e inventario (1712-1745); Libro 96-42: Libro $4^{\circ}$ de Carta Cuenta e inventario (1748-1887); Libro 96/53: Caja con papeles de reconocimiento y licencias de obras; Libro 96/54: Caja con papeles de apeos y cuentas.
}

1668, octubre, 24 (ADO-S, Libro 96/40, f. 92v): [Al margen: El señor Godoy manda hacer la torre] Porque Su Ilustrísima reconoció por vista de ojos que lo más de que necesita la fábrica de la iglesia es de una torre para las campanas (...) dio su ilustrísima y mandó que se haga dicha torre, guardando en las cédulas que para ello se han de poner posturas y remates, escrituras y plazos y condiciones de la obra, lo que en esta parte dispone la constitución sinodal de este obispado.

1672, octubre, 25 (ADO-S, Libro 96/40, ff. 117r118r): Primeramente da por descargo el dicho Lázaro Pérez, como tal mayordomo, 1.870 reales de vellón que con licencia del tribunal pareció haber pagado a Andrés Martínez, el mayordomo que fue de la dicha iglesia, a Francisco del Molino Hermosa, maestro de cantería y persona que estaba haciendo la obra de la torre de la iglesia de esta villa, los cuales se le dieron para despachar los oficiales que estaban trabajando (f. 117v) en la dicha obra, y constó de carta de pago del dicho Francisco del Molino Hermosa por ante Simón de Miranda, notario apostólico, su fecha en Calatañazor, a 22 de septiembre de 1670 años. || (f. 118r) Se le pasan en cuenta al dicho mayordomo 7.625 reales de vellón que pareció haber pagado a Francisco de Molino Hermosa, maestro de cantería, para materiales de la dicha obra de la torre y para su gasto suyo y de sus oficiales, como constó de su carta de pago firmada de su nombre en esta villa a 12 de octubre de [1]671. || Se le reciben y pasan en cuenta 20.226 reales que pareció haber pagado a Simón Gutiérrez y Juan de Lamier, Bartolomé Cobo y Antonio del Molino y a otros oficiales que asistieron a la dicha obra de la torre para los jornales que por el tribunal se les señalaron, como constó por cartas de pago de los susodichos.

1672, octubre, 25 (ADO-S, Libro 96/40, ff. 120v123r): Da por descargo el dicho mayordomo y se le pasan en cuenta 2.430 reales que pareció haber pagado a (f. 121r) Vicente del Molino y oficiales de la dicha obra de la torre para su sustento por los jornales que se les señalaron por el tribunal de este obispado, que vino remitida al licenciado Francisco la Molinera, beneficiado de esta villa, y al dicho Lázaro Pérez, mayordomo, que todo se gastó este presente año de 1672 y constó por cartas de pago del dicho Vicente del Molino, maestro, y uno de los obligados en la dicha obra de la torre. || Se le pasan en cuenta al dicho mayordomo $2.745,5$ reales que pareció haber pagado a Miguel Casado y Domingo Ortego y a Juan Casado, Andrés Ibáñez y Juan Fernández y Juan de Pascual y a otras diferentes personas que han traído con carretas la piedra labrada de la villa de Talveila y Cubilla, 
y piedra para la mampostería de la obra de la dicha torre y la arena que fue necesaria, como todo constó por cartas de pago de las personas que hicieron los dichos acarretos, y de la licencia que para ello tuvo el licenciado Francisco la Molinera, beneficiado de esta villa, el licenciado Luis García, caballero beneficiado de la dicha villa, y a Lázaro Pérez, mayordomo de la iglesia. Su fecha en el Burgo, a 14 de mayo de este presente año de 1672. || (f. 121v) Se le pasan en cuenta 540 reales que se pagaron a Juan Langre y Domingo Langre, oficiales que trabajaron en la dicha obra, en que alcanzaron al maestro, además del sustento, como constó de carta de pago de Vicente del Molino, maestro de dicha obra. || Se le pasan en cuenta al dicho mayordomo 1.258 reales que los susodichos, en virtud de la dicha licencia, pagaron a Bartolomé Cobo, Juan del Cotero, Jerónimo del Cotero, Nicolás Crespo y Antonio del Molino, oficiales de la dicha obra, en la cual dicha cantidad alcanzaron al maestro de los jornales que ganaban, además del sustento que por el dicho tribunal se les mandó dar, como constó de carta de pago de los susodichos, que todos sabían firmar. || Se le pasan en cuenta 59 reales que pagaron a Vicente del Molino, maestro de la obra. || (f. 122r) Se le pasan en cuenta al dicho mayordomo 718 reales que pareció haber pagado del sustento de algunos oficiales y de la madera que se compró para la escalera de la torre y garita y tablones para los suelos. || Se le pasan en cuenta 367 reales que pareció haber pagado a Hernando de Arbaira, maestro de carpintería, por cuenta de 880 reales en que se remató la obra de carpintería de la torre, suelos y escalera. $\|$ Se le pasan en cuenta al dicho mayordomo 40 reales que pagó a Francisco Martínez, vecino de esta villa, de los portes del agua para la dicha obra. \| (f. 122v) Se le reciben y pasan en cuenta al dicho mayordomo 200 reales que por carta de pago que mostró pareció haber pagado a Juan Antonio Pérez de Villarreal, maestro de carpintería, por la ocupación y trabajo que tuvo en ver la obra de la torre de esta villa que hicieron Francisco del Molino y Vicente del Molino, como persona que fue nombrada por los señores provisores para el dicho efecto. || (f. 123r) Se le pasan en cuenta al dicho mayordomo 237 reales que pareció ir de yerro en la segunda partida de los jornales de Bartolomé Cobo, Juan del Cotero y compañeros, porque habiendo de dar carta de pago de 1.495 reales que recibieron solo la tienen dada de 1.258 , y por olvido no la dieron de los 237 reales del yerro que lo habían recibido antes para que estuviese todo en una partida, porque parte tenían dado recibo de ellos, de que constó y además de esto lo declaró el licenciado Francisco la Molinera, que les pagó dicha cantidad.
1674, octubre, 29 (ADO-S, Libro 96/40, f. 145r-v): Se le pasan en cuenta al susodicho [mayordomo] 16 reales que se gastó en limpiar el cementerio y echar cantidad de tierra contra iglesia por el daño de las canales. $\|$ (f. 145v) Se le pasan en cuenta al dicho mayordomo 120 reales de vellón que se le dan por 25 días que se ocupó en ir a la villa del Burgo y Rabanera y Hontoria con negocios tocantes al pleito de la torre que se ha hecho sobre el litigio con los fiadores de Molinos. || Se le pasan en cuenta al dicho 100 reales de vellón por otros tantos que dicho mayordomo dio y pagó a Juan de Santos García, receptor de la Audiencia Episcopal de Osma, por su trabajo y salarios del tiempo que se ocupó en hacer la información que se hizo en esta villa sobre el pleito de la torre, con orden del tribunal.

1698, enero, 13 (ADO-S, Libro 96/40, f. 295r-v): Se le reciben y pasan en cuenta a dicho mayordomo 120 reales de vellón por los mismos que por libran- / za dicho señor juez dio y pagó a Juan García Pedraza, vecino de la ciudad de Soria, en virtud del poder que tenía de la heredera del mayorazgo de Marquina, por el arco y piedras sillares que están puestas en el cementerio de la iglesia, en que otorgó venta de dichas piedras y arco a favor de dicha iglesia...

1738, enero, 9 (ADO-S, Libro 96/41, f. 174r): Se le abonan a dicho mayordomo 180 reales de vellón que ha tenido de costo el archivo, fijado en la sacristía nueva, según al presente se halla. || Da en data 127,5 reales de vellón del costo de la puerta nueva de la sacristía, en que entra el gorrón y quicio y portal. Se le abonan. $\|$ Se le abonan 82 reales de vellón que tuvo de costo el levantar el suelo de la sacristía vieja, así de madera, jornales y clavazón, como se justificó por el memorial que para ello se formó.

1747, noviembre, 25 (ADO-S, Libro 96/42, ff. 221v-222r): Es data 1.189,5 reales de vellón, los mismos que se han ganado en hacer 104 tapias y media para cerrar la claustra, incluyendo en esta cantidad los jornales de oficiales, coste de cal, conducción de arena, agua y piedra. || Es data 233 reales y 2 mrs de vellón, los mismos que ha tenido de coste la piedra que se sacó del castillo, con licencia del excelentísimo señor duque, conducción, hacer el andamio y componer el estribo que está contiguo y refrescos que se dieron a las personas que quedaron cuidando la iglesia por de noche, mientras estuvo abierta la ventana. || (f. 222r) Es data 350 reales y $16 \mathrm{mrs}$ de vellón que ha tenido de coste la pared del baptisterio, componer la de la huesera, entrando la conducción y coste de materiales. 
1750, abril, 10 (ADO-S, Libro 96/42, f. 55r): Se le pasa en data 7.345 reales de vellón que costó la obra de la bóveda y coro de dicha iglesia; consta de recibos del maestro.

1756, agosto, 7 (ADO-S, Libro 96/42, f. 100v): [al margen: Hubo ruina en el baptisterio de notable consideración] Que se haga dos colaterales en la capilla mayor, que suban a más de la mitad del lienzo, con el ancho correspondiente, para que la iglesia tenga la decencia que no tiene, buscando maestros de toda satisfacción que las ejecuten con arte, y de solo medio relieve y una buena arquitectura, y para ello se da comisión al cura actual...

1767, enero, 12 (ADO-S, Libro 96/53, pliego suelto): ...que respecto que uno de los días por la noche del mes de diciembre próximo pasado escalaron la dicha iglesia, quebrantando y falseando doce cerrajas y aunque no faltó alhaja alguna de dicha iglesia, para su seguridad es necesario cerrar de cal y canto la puerta que sale del baptisterio a la claustra, por no ser útil, antes bien de mucho perjuicio a dicha iglesia. Asimismo, quitar el balcón de la sala que hay encima de la sacristía, como también en su lugar hacer una ventana con su buena reja de hierro, y los tabiques que hay en dicha sala derribarlos y hacer una pared madre encima de la sacristía que cerque toda dicha sala con sus esquinas y ventanas de sillería, echando en estas y en las de la sacristía de la capilla de la Concepción / y ventana del baptisterio buenas rejas de hierro. Asimismo, barrear las puertas principales de dicha iglesia y sacristía con las planchas de hierro correspondientes y necesarias, como también poner una puerta en el paso de la entrada de la capilla de la Concepción con su cerradura correspondiente. Y asimismo quitar el portegado que hay arrimado a dicha iglesia, y el de dentro de la claustra, para evitar el subir a las ventanas ni tejado por no ser útiles para cosa alguna, y que los materiales de estos se aprovechen a favor de dicha iglesia...

1767, enero, 26. Burgo de Osma (ADO-S, Libro 96/53, pliego suelto): Digo que en uno de los días del mes de diciembre próximo pasado el año de 17[66], a deshora de la noche, escalaron la expresada iglesia, quebrantando y falseando doce cerrajas, aunque no pudieron conseguir los delincuentes, o no quisieron, quitar alhaja alguna de la iglesia mencionada, se hace preciso para obviar otro semejante lance, y el que extraigan y roben dichas alhajas y que queden aseguradas, el cerrar de cal y piedra la puerta que sale del baptisterio de la claustra, la que es enteramente inútil y perjudicial a la iglesia, y asimismo es útil y conveniente el quitar el balcón de la sala que hay encima de la sacristía y en su lugar poner una ventana con una reja fuerte de hierro, derribar los tabiques que hay en la sala de que va hecha mención y hacer una pared maestra encima de dicha sacristía que cerque toda la dicha sala con sus esquinas y ventanas de sillería, / y echar en las de la sacristía de la capilla de la Concepción y ventana de dicho baptisterio unas fuertes rejas de hierro, y barrear las puertas principales de la enunciada iglesia y sacristía con las planchas de hierro necesarias, y asimismo es conveniente y preciso para el fin recordado poner una puerta en el paso de la entrada de dicha capilla de la Concepción con su cerradura y quitar el portegado que hay y está arrimado a la expresada iglesia y el de dentro de la claustra, para evitar el subir a las ventanas ni tejado por ser inútiles, y se pueden aprovechar todos sus materiales para hacer y fabricar cuanto va relacionado...

1767, septiembre, 24 (ADO-S, Libro 96/53, pliego suelto): Ante su merced dicho señor juez de comisión pareció presente Pedro Aguilera, residente en dicha villa, maestro de cantería y carpintería, [...] quien ofreciose declarar y reconocer por menor las obras que se citan en la petición de estos autos y, habiéndolo ejecutado, declaró lo siguiente. Primeramente declaró ser preciso cerrar la puerta que sale del baptisterio a la claustra con buena mampostería de cal, dejando una ventana / de sillería con su reja en cruz, poner dicha puerta en un todo inútil y perjudicial a dicha iglesia y esto tendrá de coste 190 reales. Asimismo declaró ser muy útil y necesario a dicha iglesia el quitar un balcón de madera que hay encima de la sacristía, como también un tabique que allí mismo hay, y en su lugar se ha de hacer una pared de mampostería de cal y piedra, dejando una ventana de sillería proporcionada con su reja, que tendrá de coste 593 [reales]. Declaró débese reparar en toda forma un estribo que está encima de la sacristía, sacando las piedras que tiene rompidas y poniendo otras de sillería, de modo que la esquina quede bien enlazada y unida, y que también se ha de quitar una zarza con sus raíces que hay en lo alto del estribo, descubriendo bien todo el remate y amacizándolo de nuevo con cal y piedra, y el vertiente para las aguas ha de ser de sillería según arte. También se ha de calicostrar y tapar los agujeros en la pared de la iglesia según y cómo sea necesario, como también el recorrer todo cimiento de la sacristía y baptisterio por hallarse por muchas partes devorado, lo que tendrá de coste 308. También se ha de dar de cal a la pared que baja desde la esquina del baptisterio a las peñas, / cerrando los portillos que se hallan para evitar la subida por aquella parte, que tendrá de coste 60 . Declaró 
ser necesario el quitar los dos portegados que hay, el uno bajo la puerta de la iglesia y el otro en la claustra, por ser peligrosos a dicha iglesia y de los que se ha de aprovechar piedra y materiales que tiene para lo necesario de la obra de la iglesia, lo que tendrá de coste 40 . Declaró y dijo que para mayor seguridad de dicha iglesia se hace necesario hacer cerraja nueva para la puerta de la iglesia y guarnecer dicha puerta con unas planchas de hierro, como poner rejas en la ventana del baptisterio y sacristía, lo que tendrá de coste 200 reales. Todos los cuales reparos declaró bajo del juramento. [Todo ascenderá] a 1.391 reales.

1770, junio, 10. Cabrejas del Pinar (ADO-S, Libro 96/53, pliego suelto): Para hacer el transparente arriba mencionado se hará un rompimiento a todo el grueso de la pared, que es lo que va demostrado en su planta, y lo alto lo que representa en su alzado, para poder / guarnecerla de sillería conforme se demuestra, por fuera y por dentro se hará lo restante de su grueso de un arco fuerte de rajola para contener el peso de la pared de dicho rompimiento, macizándolo bien para su seguridad, y contemplando lo elevado del sitio por aquella parte lo fuerte de la pared, y lo estéril de materiales, digo yo, Juan Antonio Miguel, maestro arquitecto, que habiendo reflexionado el coste de las tres mencionadas obras me parece llegará como a 7.000 reales de vellón, y por verdad lo firmo...
1775, diciembre, 13 (ADO-S, Libro 96/42, ff. 240v-241r): Es data 17 reales que ha costado una cerraja y cerrojo / para la puerta de la claustra de abajo.

1790, abril, 30 (ADO-S, Libro 96/42, f. 325r-v): 1.998 reales que costó la construcción de la portada de piedra para la sacristía. $\| 1.868$ reales que ha costado la construcción de piedra del archivo. || (f. 325v) Son data 1.692 reales que ha costado el allanar y ensanchar la sacristía, terraplenar la Concepción y hacer las paredes de la claustra.

1792, mayo, 4 (ADO-S, Libro 96/42, f. 333v): Son data 842 reales que ha pagado a Cipriano Antonio Miguel, maestro director de las obras del púlpito, archivo y puerta de la sacristía por los planes y trazas. \| Son data 3.435 reales y $31 \mathrm{mrs}$ del coste, conducción y colocación de las puertas del archivo que se ha hecho para dicha iglesia, los 3.000 del coste y los restantes de su conducción y colocación.

1810, octubre, 2 (ADO-S, Libro 96/39, s.f.): 116 reales de vellón que ha importado el componer el transparente de Nuestra Señora del Castillo. || 6.000 reales de vellón que se le prometieron y gratificaron al capitán de guardia cuando en el 21 de noviembre de 1808 se acampó en esta villa y sus confines la tropa francesa, porque puso guardia en la puerta de la iglesia para que no fuese saqueada como otras lo fueron. 